\title{
Um Modelo de Ciências para Fundamentar a Introdução de Aspectos de Natureza da Ciência em Contextos de Ensino e para Analisar tais Contextos
}

\author{
A Model of Science to Base the Introduction of Aspects of \\ Nature of Science in Teaching Contexts and to Analyse such \\ Contexts
}

\author{
Monique Santos \\ Brasil \\ Poliana Maia \\ Brasil \\ Rosária Justi \\ Brasil
}

\begin{abstract}
Alguns pesquisadores da área de Educação em Ciências têm destacado a importância de introduzir aspectos de Natureza da Ciência de maneira contextualizada e/ou explícita e/ ou integrada, no ensino de Ciências. Diferentes abordagens alternativas, consideradas contemporâneas e amplas, apresentam $o$ que introduzir, mas nenhuma delas caracteriza didaticamente o significado de cada um desses aspectos de Natureza da Ciência. Visando contribuir para o preenchimento dessa lacuna, adotamos como aporte teórico deste artigo uma dessas abordagens e a ampliamos. Para isto, estudamos cada uma das diferentes perspectivas disciplinares presentes em tal abordagem. Assim, caracterizamos tais perspectivas disciplinares, isto é, identificamos e detalhamos o significado dos aspectos de Natureza da Ciência relacionados a cada uma delas, bem como seus limites e alcances, e alteramos sua representação visual analógica. Como consequência, a nova versão da abordagem, além de poder ser utilizada por professores no planejamento de situações de ensino mais autênticas, também poderá ser utilizada por pesquisadores na análise de dados coletados em contextos de ensino. Ambas funções são explicadas e exemplificadas neste artigo a partir de alguns estudos que já foram ou estão sendo desenvolvidos em diferentes níveis de ensino. Discutindo ambas funções, identificamos implicações para o ensino de Ciências na Educação Básica, formação de professores e pesquisa na área.
\end{abstract}

Palavras-chave: Natureza da Ciência; Ensino de Ciências; Ferramenta Teórica; Ferramenta Metodológica.

Some Science Education researchers have emphasised the importance of discussing aspects of Nature of Science, in a contextualised, and/or explicit, and/or integrated manner within science teaching. Distinct alternative approaches, known as contemporary and comprehensive ones, identify what to introduce in science teaching; however, none of 
them didactically characterise the meaning of su ch aspects of Nature of Science. Seeking to contribute to filling this gap, in this paper we have adopted one of these approaches as the theoretical background and have expanded it. For this, we have studied each of the disciplinary perspectives that are part in such an approach. Thus, we characterise such disciplinary perspectives, meaning that we identify and detail the meaning of the aspects of Nature of Science related to each of them, as well as their scopes and limitations. This also results in changes to its visual representation, an analogue-based one. As a result, the new approach can be used both by teachers, in planning more authentic teaching situations, and by researchers in analysing data collected in teaching contexts. Both functions are exemplified in this paper, being taken from some studies that have been, or are being, conducted. By discussing both functions, we identify consequences for science teaching in basic education, for teacher education and for research in the area.

Keywords: Nature of Science; Science Teaching; Theoretical Tool; Methodological Tool.

\section{Introdução}

Nos últimos anos, foram publicadas algumas pesquisas na área de Educação em Ciências ${ }^{1}$ que enfatizam a importância de a educação científica ser mais autêntica (por exemplo, Archer et al., 2010; Millar \& Osborne, 1998; Osborne et al., 2003), isto é, envolver situações de ensino que sejam mais próximas da Ciência (Gilbert, 2004). Esta postura é coerente com o objetivo de promover uma alfabetização científica mais ampla, que contribua para a formação de cidadãos crítico-reflexivos (Sasseron \& Carvalho, 2011), capazes de entender e refletir sobre o conhecimento científico (Roberts, 2011). Tais pesquisas têm destacado a importância de um ensino que possa contribuir para o desenvolvimento de uma visão mais ampla sobre Ciências $^{2}$, na medida em que favoreça o entendimento e a reflexão sobre os processos de construção do conhecimento científico, tais como os de produção, comunicação, avaliação, revisão e validação.

Sob esta ótica, vários pesquisadores da área têm investigado sobre a importância de se introduzir aspectos de Natureza da Ciência (NdC) no ensino de Ciências (por exemplo, Abd-El-Khalick, 2012; Allchin, 2011, 2012a, 2013, 2017; Irzik \& Nola, 2011, 2014; Justi \& Erduran, 2015; N. G. Lederman et al., 2002; Matthews, 2012). Na literatura da área, são encontradas várias definições para o termo NdC. Dentre elas, a apresentada por McComas (2008) reflete a perspectiva geral adotada neste artigo. Segundo o autor, NdC é:

[...] um domínio híbrido que combina aspectos de vários estudos sociais da Ciência, incluindo História, Filosofia e Sociologia da Ciência, combinados com a pesquisa das Ciências da Cognição, como a Psicologia, em uma rica descrição da Ciência; como ela funciona, a forma de operar dos cientistas, enquanto um grupo social; e como a própria sociedade tanto dirige como reage aos empreendimentos científicos (McComas, 2008, p. 249-250).

\footnotetext{
1 Ressaltamos que optamos pelo uso do termo Ciência(s) com a letra inicial maiúscula devido o mesmo se referir à área de conhecimento ou à disciplina escolar.

2 O termo sobre Ciências, neste artigo, é utilizado como sinônimo do termo Natureza da Ciência.
} 
Tais pesquisadores também têm enfatizado a necessidade de $\mathrm{NdC}$ ser discutida de maneira contextualizada e/ou explícita e/ou integrada (sendo que alguns deles enfatizam mais uma ou duas maneiras do que outra). A abordagem contextualizada se refere à presença de um contexto como pano de fundo, por exemplo, o contexto histórico no ensino de modelos para o átomo; a abordagem explícita se refere a discutir abertamente sobre aspectos de $\mathrm{NdC}$ que influenciam (ou influenciaram) a construção do conhecimento científico (por exemplo, a motivação de Marie Curie em explicar dados experimentais inesperados, que levou à descoberta do elemento químico Rádio); e a abordagem integrada se relaciona a incorporar aspectos de $\mathrm{NdC}$ ao desenvolvimento de um ou mais conteúdos científicos curriculares (por exemplo, a multiplicidade de, e o relacionamento entre, modelos para o átomo). Destacamos que é mais comum encontrarmos na literatura da área autores que fazem menção às, e/ou aos trabalhos baseados nas, maneiras contextualizadas e explícitas de introduzir aspectos de NdC no ensino. Contudo, trabalhos baseados nas três abordagens de maneira equilibrada, isto é, que não enfatizam mais uma ou duas delas em relação à outra são pouco comuns. Além disso, com relação à abordagem contextualizada, é importante destacar que ela se torna significativa apenas se o contexto inserido como pano de fundo da atividade for relevante ao contexto em que os estudantes estão inseridos. Com relação à abordagem integrada, entendemos que ela vai além de apenas incorporar aspectos de $\mathrm{NdC}$ no desenvolvimento de um ou mais conteúdos científicos curriculares isoladamente, ou seja, os aspectos de $\mathrm{NdC}$ devem ser incorporados aos objetivos de ensino e de aprendizagem. Dessa forma, uma abordagem contextualizada, explícita e integrada de aspectos de $\mathrm{NdC}$ no ensino de e sobre Ciências, de maneira equilibrada, pode favorecer não apenas a aprendizagem de conteúdos científicos curriculares como o desenvolvimento de uma visão mais ampla sobre Ciências, na medida em que potencializa a construção do conhecimento de e sobre Ciências em seus contextos de construção, com seus limites e alcances, aproximando os estudantes desses contextos.

Nesse sentido, Driver et al. (1996) não apenas reconhecem a importância de se inserir aspectos de $\mathrm{NdC}$ no currículo, como também apresentam cinco benefícios que a aprendizagem de tais aspectos pode acarretar: (i) entendimento dos processos da Ciência; (ii) tomadas de decisões ${ }^{3}$ informadas sobre questões sociocientíficas; (iii) apreciação da Ciência como um elemento essencial da cultura contemporânea; (iv) consciência das normas da comunidade científica; e (v) aprendizagem do conteúdo científico curricular com mais profundidade. Entretanto, mais de duas décadas depois, ao analisar o currículo de nove países, Olson (2018) mostrou que raramente (com exceção do currículo da Austrália) os aspectos de $\mathrm{NdC}$ são apresentados como objetivos de aprendizagem.

Portanto, apesar do consenso entre pesquisadores da área sobre a importância e os benefícios de se inserir aspectos de NdC no currículo (Martins, 2015), Olson (2018) mostra que tal dimensão não foi apropriada pelos currículos ao redor do mundo como

3 A nosso ver, nem sempre será possível ou necessário que o estudante tome uma decisão. Em Justi et al. (2019), apresentamos uma discussão aprofundada sobre essa questão. 
objetivos de aprendizagem. Dessa forma, é pertinente considerar que há um problema em alguma das dimensões a respeito da introdução de aspectos de $\mathrm{NdC}$, seja na dimensão $o$ que introduzir (isto é, quais aspectos de $\mathrm{NdC}$ - foco deste artigo) seja na de como introduzir (Allchin et al., 2014; Irzik \& Nola, 2011; Matthews, 1998).

Com relação a o que inserir no currículo, alguns pesquisadores (por exemplo, AbdEl-Khalick et al., 1998; N. G. Lederman, 2006; N. G. Lederman et al., 2002) acreditam que é possível e necessário elencar certos aspectos de $\mathrm{NdC}$ que eles julgam serem relevantes. Nessa perspectiva, Norman Lederman e seus colaboradores propuseram uma lista de sete princípios que deveriam ser ensinados aos estudantes: (i) o conhecimento científico é provisório; (ii) o conhecimento científico tem caráter empírico; (iii) o conhecimento científico é norteado por teorias; (iv) o conhecimento científico é produto da criatividade e imaginação humanas; (v) o conhecimento científico é influenciado pelos contextos cultural e social; (vi) existem diferenças entre observação e inferência; e (vii) existem diferenças entre leis e teorias científicas (N. G. Lederman, 2006).

Como destacado por Deng et al. (2011), a partir dessa proposição e do amplo consenso entre pesquisadores da área e documentos curriculares internacionais, vários estudos empíricos foram realizados tendo como objetivo, principalmente, caracterizar a visão de estudantes e professores sobre Ciências, assim como propor e validar instrumentos ${ }^{4}$ para realizar tais caracterizações. A publicação desses estudos resultou em uma ampla divulgação de tal proposta, como evidenciado pelo grande número de publicações que utilizam a lista de princípios como aporte teórico (por exemplo, Bayir et al., 2014; Cakici \& Bayir, 2012; J. S. Lederman \& Khishfe, 2002; J. S. Lederman \& Ko, 2002; N. G. Lederman et al., 2002; Schwartz et al., 2008). Assim, nos últimos 25 anos, tal proposta ficou conhecida na área como visão consensual de NdC (Martins, 2015), sendo predominante na literatura da área (Erduran et al. 2019). Entretanto, nos últimos anos alguns pesquisadores (por exemplo, Allchin, 2011, 2013, 2017; Erduran \& Dagher, 2014; Irzik \& Nola, 2011, 2014; Justi \& Erduran, 2015; Martins, 2015; Matthews, 2012; McComas, 2008; Nielsen, 2013; Osborne et al., 2003; van Dijk, 2011; Weinstein, 2008; Wong \& Hodson, 2010) têm criticado tal proposta. Para tais autores, os princípios apresentados na lista possuem diversos problemas, sendo os principais: (i) são apresentados de maneira declarativa; (ii) podem favorecer a visão de que a Ciência se restringe apenas a eles; e (iii) podem não favorecer o entendimento de professores por apresentar ideias oriundas da Filosofia de maneira abstrata e complexa.

Um dos críticos da lista de princípios proposta por Lederman e seus colaboradores é Allchin $(2011,2013,2017)$. Para ele, apresentar uma lista de princípios de maneira declarativa não contribui para a alfabetização científica porque a compreensão, a recordação e/ou a memorização da lista não auxiliam os estudantes a refletir, por exemplo, sobre as influências que o processo de construção do conhecimento científico pode exercer em tomadas de decisões individuais e/ou sociais conscientes. Em outras

4 Esses instrumentos são, muitas vezes, questionários envolvendo escala Likert, que recebe muitas críticas na literatura por não favorecer uma explicitação clara e/ou fidedigna das ideias dos respondentes. 
palavras, a lista de princípios não contribui para uma compreensão funcional da Ciência (Allchin, 2014).

Nesse sentido, pensando no contexto de ensino de Ciências, Allchin (2011, 2013, 2017) propôs uma abordagem alternativa à lista de princípios baseada na ideia de Ciência Integral (Whole Science, no original em inglês) que resultou na proposição do Perfil de Dimensões de Confiabilidade da Ciência (PDCC). Segundo o autor, a denominação Ciência Integral pode ser compreendida como um modo de ver a Ciência de maneira holística. Assim, para Allchin (2012b), em vez de apresentar uma lista de princípios para os estudantes, seria mais adequado apresentar, de maneira contextualizada, explícita e integrada, um perfil de dimensões que é constituído de categorias epistêmicas funcionais relacionadas a: (i) observações; (ii) métodos de investigação; (iii) instrumentação; (iv) padrões de raciocínio; (v) dimensões históricas; (vi) dimensões humanas; (vii) interações entre cientistas; (viii) dimensões socioculturais; (ix) economia e/ou financiamento; e (x) comunicação. Em suma, o que Allchin defende é que a análise dos procedimentos envolvidos nas práticas científicas e a validação do conhecimento produzido a partir delas podem ser conduzidas a partir de categorias epistêmicas funcionais que constituem tal perfil.

Baseado na perspectiva de Ciência Integral, Allchin (2013) apresenta uma coleção de estudos de casos históricos e contemporâneos com a identificação de categorias epistêmicas funcionais que podem emergir dos mesmos. Isto se mostra coerente, visto que o autor defende a perspectiva de Ciência em construção (Latour, 1987). Neste livro, ele também apresenta algumas propostas a partir das quais os estudantes podem trabalhar em grupos, estruturando ideias para se posicionar a favor ou contra determinado ponto de vista e/ou afirmação científica. Entretanto, até o presente momento (início de 2020), existem poucos estudos na literatura sobre o uso de casos baseados na perspectiva de Ciência Integral (por exemplo, Carvalho \& Justi, 2019; Justi \& Santos, 2019; Santos, 2018) no contexto de ensino de Ciências.

Em síntese, a proposta de Allchin $(2011,2013,2017)$ além de contemplar uma visão de ensino contemporânea e ampla, apresenta também uma proposta concreta de introdução de aspectos de $\mathrm{NdC}$ no ensino a partir de uma coleção de casos históricos e contemporâneos. Contudo, tal proposta se mostra limitada devido à falta de caracterização das dimensões e das categorias epistêmicas funcionais relacionadas às mesmas que constituem o PDCC. Além disso, Allchin (2011, 2013, 2017) apresenta tais dimensões e categorias agrupadas de diferentes maneiras nas referidas referências e, por esses motivos, Justi e Santos (2019) e Santos (2018) fizeram uma adaptação no PDCC para torná-lo uma ferramenta funcional e utilizá-lo em seus estudos.

Outros críticos da lista de princípios proposta por Lederman e seus colaboradores são Irzik e Nola $(2011,2014)$. Eles criticam mais intensamente a lista ao apontarem que ela caracteriza a Ciência de maneira homogênea, isto é, não considera a existência de diferentes disciplinas científicas e a especificidade de cada uma delas. Diante disso, os autores propõem uma abordagem à qual denominaram Semelhança de Família (Family 
Resemblance Approach (FRA), no original em inglês). Irzik e Nola (2011) consideram a ideia de Wittgenstein de que "os membros de uma família podem se assemelhar uns aos outros em alguns aspectos, mas não em outros" (p. 594) e, por analogia, propõem que cada uma das disciplinas científicas teria características semelhantes e diferentes em relação às outras. A partir disso, eles afirmam que não devemos definir Ciência identificando suas características universais, e sim identificando características semelhantes e diferentes de cada uma de suas áreas. De acordo com a $F R A$, isto pode ser feito considerando algumas categorias relacionadas à Ciência: (i) atividades; (ii) objetivos e valores; (iii) metodologias e regras metodológicas; e (iv) produtos. Alguns anos depois, Irzik e Nola (2014) ampliaram a proposta incluindo mais quatro categorias: (v) atividades profissionais; (vi) ética científica; (vii) certificação social e disseminação de conhecimento científico; e (viii) valores sociais. Portanto, segundo essa proposta, a Ciência pode ser caracterizada como um sistema cognitivo-epistêmico, relacionado às quatro primeiras categorias, e como um sistema social-institucional, relacionado às quatro últimas. Entretanto, eles ressaltam que as duas dimensões e, consequentemente, as oito categorias, que não são exclusivas e distintas, interagem constantemente umas com as outras e de diversas maneiras.

Apesar de Irzik e Nola $(2011,2014)$ terem expressado seu desejo de que a FRA fosse utilizada no ensino de Ciências e fornecido algumas sugestões gerais para isso, eles reconhecem que tal abordagem é teórica. Um detalhamento maior sobre como seria possível utilizar tais ideias (oriundas da Filosofia) no ensino de Ciências foi proposto por Erduran e Dagher (2014). Para isso, as autoras ampliaram a proposta de Irzik e Nola $(2011,2014)$ incluindo aspectos políticos, financeiros e organizacionais na dimensão social-institucional, o que resultou em mais três categorias: (ix) sistemas financeiros; (x) estruturas de poder político; e (xi) organizações e interações sociais ${ }^{5}$. Além disso, elas propuseram um conjunto de representações visuais denominadas Imagens Geradoras da Ciência (Generative Images of Science, no original em inglês), com o objetivo de facilitar a comunicação de ideias filosóficas consideradas abstratas e complexas e, consequentemente, seu entendimento por parte de professores. A partir disso, tal abordagem que era considerada apenas teórica, passa a ser também metodológica e potencialmente aplicável no contexto de ensino de Ciências (como em Erduran et al., 2019; Kaya \& Erduran, 2016; Kaya et al., 2019). Por outro lado, a representação principal da versão ampliada da $F R A$ - chamada pelas autoras de "FRA wheel" (Erduran \& Dagher, 2014, p. 28) - se constitui de um círculo central dividido em quadrantes e circundado por dois outros, também subdivididos. Segundo as autoras:

[...] as fronteiras entre os dois círculos (ou espaços) e seus compartimentos individuais são porosas, permitindo um movimento fluido entre eles. Na realidade, esses componentes não são compartimentalizados, mas fluem naturalmente em todas as direções (Erduran \& Dagher, 2014, p. 28-29).

5 Tal ampliação é conhecida na literatura internacional como Expanded FRA, Extended FRA e Reconceptualized FRA to NOS (RFN). Destacamos que, na versão ampliada, as categorias (i) e (iv) passam a ser denominadas práticas e conhecimento, respectivamente. 
Entretanto, contrariamente aos aspectos descritos, a representação em si mostra divisões e não contém elementos gráficos que remetam à movimentação. Em função dessas divergências, consideramos que ela pode não ser facilmente entendida por professores.

Ademais, dos pesquisadores que apresentaram críticas à visão consensual de $\mathrm{NdC}$, Allchin $(2012 \mathrm{~b}, 2013)$ foi o que apresentou propostas concretas e claras de como introduzir aspectos de $\mathrm{NdC}$, de maneira contextualizada, explícita e integrada (a partir de casos históricos e contemporâneos) no ensino de Ciências.

No entanto, com relação a o que introduzir, isto é, quais aspectos de $\mathrm{NdC}$ introduzir, nem a abordagem alternativa baseada na ideia de Ciência Integral que resultou no PDCC, nem a baseada na ideia de Semelhança de Família (mesmo após a ampliação feita por outras autoras) caracterizam didaticamente o significado dos aspectos de $\mathrm{NdC}$ (denominados como dimensões e categorias epistêmicas funcionais, na primeira abordagem e como dimensões e categorias relacionadas à Ciência, na outra abordagem). Outro ponto que nos preocupa é a constatação de que visões inadequadas sobre Ciências não se limitam a estudantes, sendo identificadas também entre professores da área (Guerra-Ramos, 2012). Dessa forma, é necessário um construto que contribua para que professores, que não são especialistas em $\mathrm{NdC}$, (i) entendam o quão amplas são essas dimensões e categorias utilizadas na caracterização da construção do conhecimento científico e, ao mesmo tempo, (ii) os oriente a pensar nessas dimensões e categorias e nas múltiplas formas que elas podem se fazer presentes, em virtude da pluralidade das Ciências (isto é, reconhecendo a existência de diferentes métodos e processos de produzir, comunicar, avaliar, revisar e validar o conhecimento científico).

Nesse contexto, destacamos a importância da existência de outras propostas teóricas e metodológicas que caracterizem didaticamente o significado de cada aspecto de $\mathrm{NdC}$, para que professores de diferentes níveis de ensino tenham acesso a, e entendam sobre, o que introduzir de $\mathrm{NdC}$ no ensino de Ciências. Isto porque, segundo Kaya et al. (2019), "as próprias visões e compreensões de $\mathrm{NdC}$ dos professores podem influenciar como eles ensinam NdC" (p. 4-5). Portanto, ao elaborarmos ou ampliarmos uma abordagem alternativa para introduzir NdC no ensino, é importante nos preocuparmos com o entendimento sobre tal abordagem que professores (em exercício e/ou em formação) poderão ter (ou não) para que a introdução de aspectos de $\mathrm{NdC}$ ocorra de fato, e de maneira adequada e efetiva. Dessa maneira, assim como Moura et al. (2020), acreditamos que tais aspectos de $\mathrm{NdC}$ devem ser apropriados de maneira crítica por professores, isto é, que a partir do entendimento de uma abordagem alternativa para introduzir NdC no ensino, professores possam refletir sobre a importância de introduzir tais aspectos e sobre como introduzi-los, dependendo do nível de ensino e do contexto no qual os estudantes estão inseridos.

Diante do exposto, este artigo, que é de natureza teórica, tem como objetivos apresentar e discutir a ampliação de uma abordagem alternativa tanto à de listas de princípios quanto àquelas baseadas nas ideias de Ciência Integral e Semelhança 
de Família. Além disso, tal abordagem também pode ser chamada de modelo (e foi nomeada como tal) porque, como discutido por Gilbert e Justi (2016), modelos são artefatos epistêmicos, isto é, ferramentas de pensamento. Tal abordagem (i) identifica e detalha o significado de aspectos de $\mathrm{NdC}$ que podem ser introduzidos no ensino de forma a favorecer uma compreensão ampla do significado de Ciência, contribuindo assim para o preenchimento (mesmo que parcial) da lacuna relacionada à dimensão $o$ que introduzir de $\mathrm{NdC}$ no ensino de Ciências; e (ii) pode ser usada tanto por professores na condução do ensino de $\mathrm{NdC}$ quanto por pesquisadores na análise de situações de ensino nas quais aspectos de $\mathrm{NdC}$ foram contemplados, ampliando assim a contribuição já existente na literatura com relação ao $\mathrm{como}^{6}$ introduzir aspectos de $\mathrm{NdC}$ no ensino de Ciências. Para tanto, na próxima seção apresentamos mais uma abordagem alternativa à lista de princípios que, apesar de não ser tão conhecida quanto as demais, contempla uma visão de ensino contemporânea e ampla, assim como as outras duas abordagens alternativas apresentadas anteriormente. Contudo, nos baseamos nesta última para atingir nosso objetivo pois, de acordo com os argumentos apresentados na próxima seção, reconhecemos o potencial desse modelo para ser empregado por professores de Ciências.

\section{Modelo de Ciências para o Ensino de Ciências}

Considerando as críticas apresentadas às listas de princípios (como a proposta por Lederman e seus colaboradores); a observação de que a proposta de Allchin (2011, 2012b, 2013) pode favorecer a introdução de aspectos de NdC no ensino de Ciências; e a importância de utilizar uma representação que seja facilmente entendida por professores, favorecendo o entendimento da proposta, Justi e Erduran $(2015)^{7}$ propuseram o Modelo de Ciências para o Ensino de Ciências (MoCEC). A motivação principal das autoras foi a necessidade de fundamentar discussões amplas sobre Ciências, com professores de Ciências e voltadas explicitamente para o contexto de ensino de Ciências. Tal modelo se baseia em duas premissas: (i) a Ciência é uma complexa atividade cognitiva, epistêmica e social, que pode e tem sido caracterizada a partir de uma série de perspectivas disciplinares; e (ii) os argumentos sobre Ciências devem se basear em evidências oriundas de perspectivas disciplinares distintas para que a Educação em Ciências favoreça o desenvolvimento de uma visão mais ampla sobre Ciências (Justi \& Erduran, 2015).

As diferentes perspectivas disciplinares apresentadas no MoCEC são:

- Antropologia da Ciência, que considera o trabalho científico como uma forma de ação social, e que o desenvolvimento do conhecimento científico é uma forma de produção cultural;

6 Neste artigo, nos referimos a como em sentido amplo, ou seja, como não se refere a aspectos operacionais (por exemplo, etapas a serem seguidas para elaboração e/ou condução de atividades), e sim aos princípios gerais para orientar a introdução de $\mathrm{NdC}$ no ensino (por exemplo, áreas de conhecimento e aspectos de $\mathrm{NdC}$ relacionados às mesmas a serem contemplados em tais atividades).

7 Apesar de a publicação original ser de 2015, tal modelo foi elaborado em 2012, concomitantemente à proposta de Erduran e Dagher (2014). 
- Psicologia da Ciência, que estuda o comportamento e os processos mentais dos cientistas, assim como aspectos de neurociência;

- Sociologia da Ciência, que estuda tanto o papel central da comunidade científica na sociedade quanto os impactos da sociedade na Ciência;

- Economia da Ciência, que estuda a influência dos fatores econômicos no comportamento dos cientistas, a distribuição dos recursos financeiros destinados à Ciência, e as operações financeiras praticadas pelas instituições científicas;

- Filosofia da Ciência, cujos principais focos de interesse são o próprio significado de Ciência e seus aspectos epistemológicos, ou seja, aqueles relacionados à produção do conhecimento científico, às suas origens e à sua validação;

- História da Ciência, que estuda o desenvolvimento da Ciência e dos conhecimentos científicos ao longo do tempo, evidenciando assim que o conhecimento científico é provisório; e

- Cognição da Ciência, que estuda os processos de aquisição de conhecimento, ou seja, como os indivíduos pensam ao produzir e/ou entender o conhecimento científico e os tipos de raciocínios que eles podem usar nesse processo.

Visando favorecer a visualização do que seria considerar a Ciência a partir dessas perspectivas disciplinares, as autoras propuseram uma representação visual analógica, à qual denominaram Science Eye (Figura 1).

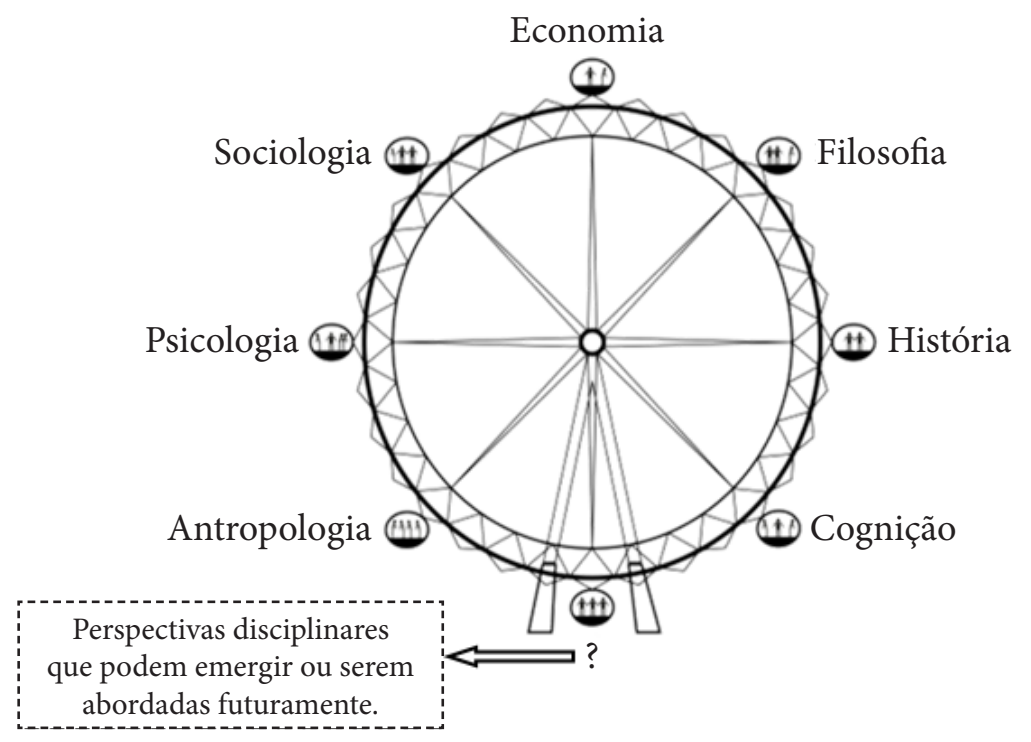

Figura 1. Science Eye - Representação visual do MoCEC adaptada de Justi e Erduran (2015, p. 7)

Tal representação foi elaborada em analogia à London Eye, que é uma das maiores rodas-gigantes de observação do mundo (135 metros de altura), situada em Londres. A analogia à London Eye foi estabelecida considerando inicialmente que: (i) assim como a visão de Londres, a da Ciência é ampla e extremamente complexa; e (ii) como cada cápsula de vidro transparente representa uma perspectiva disciplinar, cada uma delas 
pode fornecer uma orientação diferente para a visão de Ciência. Além disso, a Ciência pode ser visualizada a partir de uma única cápsula (na perspectiva de um indivíduo que está dentro de uma delas) ou de várias ao mesmo tempo (na perspectiva de um observador externo). Tal visão também pode ser diferente dependendo: (i) da posição que o indivíduo ocupa dentro da cápsula (isto é, se adota diferentes referenciais para discutir cada perspectiva disciplinar); (ii) de se ele se movimenta ou não (isto é, se busca novas maneiras de pensar em uma mesma perspectiva disciplinar); e (iii) da quantidade de indivíduos dentro da cápsula (isto é, se um cientista trabalha sozinho ${ }^{8}$ ou em grupo) (Figura 2).

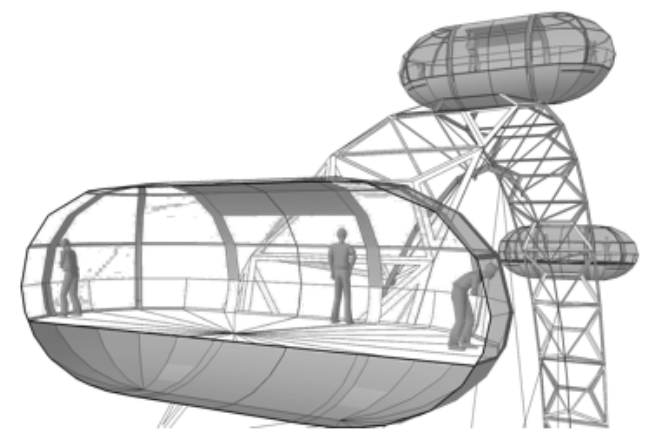

Figura 2. Número distinto de indivíduos dentro das cápsulas da Science Eye que representam visões distintas em determinadas perspectivas disciplinares (Justi \& Erduran, 2015, p. 8)

Na Figura 1, existe também um ponto de interrogação associado a uma das cápsulas, indicando que uma ou mais perspectivas disciplinares podem emergir ou serem abordadas em contextos específicos, evidenciando assim que o modelo está aberto a modificações. Portanto, a intenção das autoras ao apresentar essas perspectivas disciplinares não era que elas fossem exaustivas, mas sim representativas.

O principal objetivo das autoras de fundamentar discussões com professores de Ciências sobre Ciências a partir do MoCEC é o de que eles possam utilizá-lo como suporte no planejamento de situações de ensino mais autênticas. Elas destacam também que, como consequência da possível existência de visões divergentes em cada uma das perspectivas disciplinares, é possível que, em momentos e contextos adequados, o professor as aborde, favorecendo, assim, o desenvolvimento de uma visão ampla sobre Ciências por parte dos estudantes.

Ademais, pensando no MoCEC como suporte no planejamento de situações de ensino mais autênticas, as autoras mencionam que o modelo não propõe que todos as características relacionadas a todas as perspectivas disciplinares sejam discutidas com os estudantes em apenas um momento. Ao contrário, elas afirmam que é papel do professor decidir quais características de quais perspectivas disciplinares ele abordará (ou não) no ensino de um determinado conteúdo científico curricular em um determinado contexto educacional. Isto porque, assim como Allchin (2011, 2013, 2017), Justi e Erduran (2015) também defendem que os aspectos de $\mathrm{NdC}$ sejam introduzidos de maneira

8 Esse aspecto é enfatizado no modelo por que a ideia de que cientistas trabalham sozinhos é uma concepção muito comum entre estudantes e professores. 
contextualizada, explícita e integrada.

A nosso ver, este modelo apresenta algumas vantagens em relação às outras propostas anteriormente apresentadas e discutidas. Em especial, ele (i) apresenta uma visão ampla de Ciência ao destacar explicitamente várias perspectivas disciplinares pertinentes à mesma; e (ii) tende a ser compreendido por professores uma vez que utiliza uma representação explicitamente analógica na qual suas principais características são facilmente perceptíveis. Por outro lado, identificamos que, assim como em outras propostas, a caracterização dessas perspectivas disciplinares se restringe a uma definição de cada uma delas, o que pode não favorecer a compreensão do professor sobre seus significados, resultando em seu objetivo não ser plenamente alcançado. Disso emergiu a principal motivação para ampliar o modelo.

Ao mesmo tempo, considerando a potencialidade do MoCEC como suporte para professores no planejamento de situações de ensino mais autênticas, concluímos que seria interessante se o modelo também pudesse ser utilizado como uma ferramenta de análise de dados obtidos em contextos de ensino nos quais professores o tivessem utilizado. Para tanto, era essencial que a caracterização das perspectivas disciplinares fosse ampliada. Assim, a questão que motivou esta pesquisa foi: como ampliar o Modelo de Ciências para o Ensino de Ciências visando sua utilização tanto como suporte na introdução de aspectos de Natureza da Ciência em contextos de ensino quanto como ferramenta de análise de dados coletados em tais contextos?

\section{Aspectos Metodológicos}

Para subsidiar a discussão desta questão de pesquisa, inicialmente fizemos uma revisão da literatura das diferentes áreas de conhecimento para que, a partir daí, pudéssemos reconhecer os limites e alcances de cada uma das perspectivas disciplinares presentes no MoCEC (Figura 1). Para isso, e visando favorecer o entendimento do modelo pelo professor (principalmente) e/ou pesquisador, identificamos características de cada uma das áreas de conhecimento que permitiram apresentá-las de forma clara e sucinta, delimitando seus objetos de estudo, assim como os principais aspectos de $\mathrm{NdC}$ que elas abordam e contribuem para caracterizá-las (apresentadas na próxima seção). Iniciamos pela área de Filosofia da Ciência devido ao seu papel central, uma vez que a Ciência ocidental teve início com os filósofos da Grécia Antiga, resultando em, antes de se estabelecer como área específica, a Ciência ter sido uma parte da Filosofia (como também ocorreu com outras áreas de conhecimento ou disciplinas ${ }^{9}$, por exemplo, Biologia, Física, Geometria, Lógica, Psicologia (Rosenberg, 2005)).

Entretanto, áreas que se "separaram" da Filosofia deixaram para a mesma questões cujas respostas fogem de seu escopo. Por exemplo, o fato de a Matemática trabalhar com números não quer dizer que a mesma tenha respostas para a pergunta o que é $o$

9 Entendemos como áreas algo mais amplo, por exemplo, Filosofia, Psicologia, Antropologia, Sociologia, Economia, História. Por outro lado, disciplinas seriam mais específicas, parte de uma área (por exemplo, Biologia, Física, Matemática). 
número? Quando se pergunta sobre o significado de número, não estamos nos referindo ao significado de cada numeral que o representa. Neste caso, trata-se de uma pergunta mais ampla, que a própria Matemática não responde e não busca responder (Rosenberg, 2005).

Portanto, a Filosofia é indispensável à Ciência, uma vez que a mesma pode ajudar no entendimento das outras áreas, por possibilitar um olhar mais amplo ("filosófico") sobre cada uma delas. Ademais, de acordo com Rosenberg (2005), questões sobre Ciências, isto é, que envolvem características, limites e alcances de seus objetos e métodos de estudo, são questões para as quais tanto cientistas quanto filósofos podem prover respostas. Ainda de acordo com Rosenberg (2005), a "reflexão sobre a forma como os resultados científicos contemporâneos e as teorias influenciam a Filosofia mostra que cada um é indispensável para entender o outro" (p. 1). Nessa perspectiva, a grande área Filosofia é um pré-requisito fundamental para a compreensão de outras áreas como Filosofia da Ciência, Psicologia da Ciência, Antropologia da Ciência, Sociologia da Ciência, Economia da Ciência, História da Ciência, entre outras.

Sendo assim, Filosofia é uma área complexa e, como tal, difícil de ser caracterizada de forma simples, uma vez que seus aspectos podem estar presentes (explícita ou implicitamente) em todas as outras áreas, ou seja, a Filosofia dialoga com as demais áreas. Nesse sentido, propusemos mudanças no MoCEC com o objetivo de que a Filosofia seja compreendida tanto como uma área de conhecimento (Filosofia da Ciência) quanto como uma "base filosófica" para as demais áreas. Ao utilizarmos a expressão "base filosófica" estamos considerando o significado de "base" como o que é utilizado como suporte ou sustentação e que, muitas vezes, não é visível. Assim, contemplamos o diálogo (explícito ou implícito) da Filosofia com outras áreas. Além disto, a proposição do elemento "base filosófica" também resolve um problema identificado em um trabalho empírico posterior. Lima (2017) tentou identificar os conhecimentos de conteúdo de $\mathrm{NdC}$ de professores em formação que participaram de atividades envolvendo fatos e controvérsias históricas nos quais aspectos de $\mathrm{NdC}$ foram explicitados. A autora utilizou o MoCEC como referencial teórico para sustentar sua análise, mas teve dificuldades em reconhecer os limites e alcances de cada perspectiva disciplinar exatamente pela presença de "elementos da Filosofia" associados a essas perspectivas. Ao reconhecermos que elementos de quaisquer das perspectivas disciplinares podem ser expressos a partir de um "olhar filosófico", facilitamos a categorização de dados a partir do modelo, uma vez que as categorias dele derivadas se tornam mais claramente explicitadas.

Além desta modificação, substituímos o termo "perspectivas disciplinares" utilizado por Justi e Erduran (2015) por "áreas de conhecimento", uma vez que entendemos que essa mudança contribui para enfatizar que cada cápsula do modelo se refere a um corpo de conhecimentos mais amplo, com possíveis subdivisões internas, de acordo com as perspectivas assumidas.

Em seguida, caracterizamos o que cada uma das áreas de conhecimento se propõe a estudar, isto é, seus limites e alcances. Para isso, analisamos produções 
específicas de algumas áreas, buscando caracterizar cada uma delas e, ao mesmo tempo, identificar e detalhar o significado de seus respectivos aspectos de $\mathrm{NdC}$. Assim, estudamos detalhadamente referências específicas nas quais nos baseamos para discutilas, por exemplo, na área de Psicologia da Ciência: Feist (2012), Feist e Gorman (1998), Osbeck et al., (2011), Shadish et al. (1994), Shadish et al., (1989); na área de Cognição da Ciência: Dunbar (2002), Dunbar e Blanchette (2001), Giere (1992, 1998, 2002); na área de Antropologia da Ciência: Knorr-Cetina (1999), Laraia (2001), Marcus e Fischer (1986), Pickering (1995); na área de Sociologia da Ciência: Allchin (2004), Cunningham e Helms (1998), Latour (1987), Latour e Woolgar (1986); e na área de Economia da Ciência: Diamond Jr. (1996, 2008), Erduran e Mugaloglu (2013), Irzik (2013), Knuuttila (2013), Vermeir (2013).

Depois de realizarmos as leituras relacionadas às áreas de Psicologia e Cognição da Ciência, integramos tais áreas, pois considerar a Cognição da Ciência como uma subdivisão da Psicologia da Ciência se alinha à própria divisão interna da Psicologia, decorrente da dificuldade de separar os diferentes processos mentais e comportamentais do indivíduo. Pensando na proposição de uma segunda função para o modelo (como ferramenta de análise de dados), essa integração o torna mais funcional exatamente por eliminar a dificuldade de distinguir as duas áreas, isto é, por tornar as categorias mais excludentes.

Além das mudanças relacionadas às áreas de Filosofia, Psicologia e Cognição da Ciência, também apresentamos não apenas a caracterização de cada área de conhecimento, mas também propomos e caracterizamos didaticamente aspectos de NdC presentes nas mesmas. Tal ação pode facilitar o uso do modelo ampliado para a finalidade proposta originalmente (suporte a professores no planejamento de situações de ensino mais autênticas) e também para a finalidade adicional proposta neste artigo (ferramenta de análise de dados). Além disso, considerar aspectos ao invés de somente áreas pode contribuir não apenas para que professores entendam o significado de cada área e de o que introduzir de $\mathrm{NdC}$ no ensino de Ciências como também para que o modelo ampliado seja funcional em ambas as finalidades, na medida em que isto significa um detalhamento do significado de cada área e de cada aspecto (mesmo nos casos em que um aspecto com nome - total ou parcialmente - igual esteja presente em mais de uma área).

Durante a ampliação do modelo, identificamos outros aspectos relacionados a cada área, além dos que são apresentados na próxima seção. Porém, optamos por não incluí-los na nova versão do modelo em função de os mesmos serem muito específicos e não contribuírem para subsidiar discussões na área de Educação em Ciências.

Finalmente, com o objetivo de validar nosso modelo, ele foi discutido com os integrantes de nosso Grupo de Pesquisa (constituído por pesquisadores de diversos níveis de ensino: graduandos, professores, mestrandos, doutorandos e doutores), e com três pesquisadores especialistas na área. Como resultado, alguns aspectos de $\mathrm{NdC}$ foram inseridos ou renomeados de forma a dar mais clareza à caracterização de cada área de conhecimento. 


\section{Ampliação do Modelo de Ciências para o Ensino de Ciências}

Como discutido na seção anterior, a ampliação do MoCEC ocorreu a partir de:

- inclusão do elemento "base filosófica";

- substituição do termo "perspectivas disciplinares" por "áreas de conhecimento";

- integração da área Cognição da Ciência com a área Psicologia da Ciência;

- ampliação do significado do ponto de interrogação na representação visual analógica do modelo;

- caracterização de cada área de conhecimento;

- proposição e caracterização de aspectos de $\mathrm{NdC}$ presentes em cada uma das áreas de conhecimento; e, consequentemente,

- alteração da representação visual analógica do modelo.

Tudo isto foi feito tendo em vista os objetivos desta pesquisa de favorecer a utilização do modelo como um suporte para professores no planejamento de situações de ensino mais autênticas e como uma ferramenta de análise de dados, uma vez que ambos requerem um detalhamento maior e mais claro dos elementos apresentados no MoCEC.

Por conseguinte, essa ampliação resultou no que foi denominado por nós como segunda versão do Modelo de Ciências para o Ensino de Ciências (MoCEC v.2) e cuja representação visual é apresentada na Figura 3.

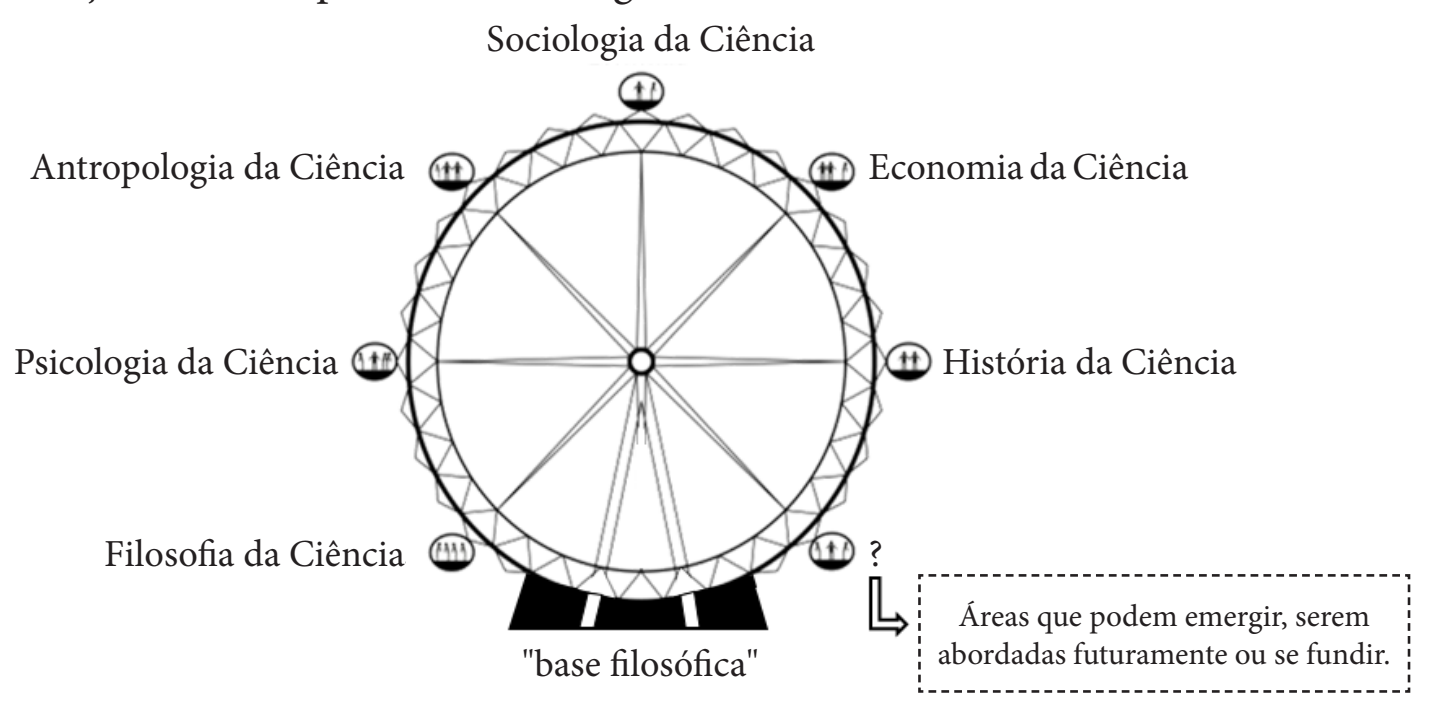

Figura 3. Representação visual do MoCEC v.2

Quando comparada com a Figura 1, a Figura 3 evidencia que, além da inclusão do elemento "base filosófica" e de a Cognição da Ciência não ter sido representada, ampliamos o significado do ponto de interrogação.

A seguir, apresentamos a caracterização de cada área de conhecimento a partir de uma síntese de o que cada uma se propõe a estudar, isto é, seus limites e alcances, assim como a identificação e o detalhamento do significado de seus respectivos aspectos de $\mathrm{NdC}$ (apresentados em ordem alfabética em função da inexistência de critérios de ordenação dos mesmos). 


\section{Filosofia da Ciência}

É uma área que estuda o significado da Ciência. Desta maneira, as principais contribuições da Filosofia da Ciência para a área de Educação em Ciências são questões especificamente, mas não exclusivamente, discutidas pelos filósofos. Essas questões podem ser relacionadas à origem, aos objetivos e à natureza das áreas de conhecimento; aos valores éticos e morais presentes em cada área; aos critérios para construção do conhecimento científico em cada área, considerando o necessário rigor metodológico. Tais questões podem também se relacionar aos processos de construção do conhecimento científico em cada uma das áreas, tais como elaboração, comunicação, avaliação, revisão e validação; e a práticas científicas e/ou epistêmicas ${ }^{10}$ utilizadas em cada uma delas, tais como investigação, observação, experimentação, análise de dados, modelagem, argumentação, entre outras.

O estudo da Filosofia da Ciência abrange o processo de construção do conhecimento científico, assim como alguns de seus aspectos:

- Epistemologia: apresenta uma reflexão do todo, ou seja, em torno da natureza, objetivos, valores, critérios, processos e práticas científicas e/ou epistêmicas sendo, portanto, um aspecto que possibilita uma reflexão dos limites e alcances relacionados à construção do conhecimento científico;

- Ética: discute os valores éticos e morais que norteiam as práticas científicas e/ou epistêmicas ou que subsidiam as decisões tomadas na área de conhecimento;

- Lógica: discute a maneira de pensar e os raciocínios relacionados à construção do conhecimento científico.

É importante destacar que, assim como a área Filosofia da Ciência é a mais ampla se comparada às demais áreas de conhecimento, seus aspectos também o são. Por isso, para se ter um olhar distanciado sobre os caminhos percorridos durante o processo de construção do conhecimento científico, faz-se necessário desenvolver um "olhar filosófico". Portanto, como mencionado na seção anterior, esses aspectos podem ser observados de forma explícita ou implícita nas demais áreas como resultado da existência do elemento "base filosófica", incluído na versão atual do modelo.

\section{Psicologia da Ciência}

É uma área que estuda os processos mentais e o comportamento do indivíduo ${ }^{11}$, no caso o cientista, durante os processos de produção e uso do conhecimento científico. Pensando especificamente nos processos mentais estudados na perspectiva da Psicologia Cognitiva, o MoCEC v.2 foca nos processos de aquisição de conhecimento, isto é, em

10 Seguindo Jiménez-Aleixandre e Duschl (2015), entendemos prática científica como aquelas que constituem processos científicos, mas que não necessariamente resultam na produção de conhecimento científico. As práticas epistêmicas, por sua vez, são compreendidas como aquelas que resultam na produção de conhecimento científico podendo, mas não necessariamente, ser também classificadas como científicas.

11 É justamente este foco no indivíduo que distingue a Psicologia da Ciência da Sociologia da Ciência, haja vista que esta última possui como foco a interação entre indivíduos na sociedade. 
como um indivíduo pensa durante a produção e o uso do conhecimento científico. Tais processos mentais são, muitas vezes, indissociáveis do comportamento do indivíduo e de outros aspectos mentais estudados por outras subdivisões da Psicologia como, por exemplo, a Psicanálise. Por esse motivo, diferentemente de Justi e Erduran (2015), optamos por incluir, nesta área, aspectos relativos à Cognição.

Considerando que o estudo da Psicologia da Ciência abrange relações intrapessoais de um indivíduo (cientista) com os processos de produção e uso do conhecimento científico, alguns de seus aspectos são:

- Complexidade: discute como, durante os processos de produção e uso do conhecimento científico, um cientista pode ter dificuldades para compreender alguma parte do mesmo devido à sua complexidade;

- Criatividade: discute a capacidade que um cientista possui para criar, produzir e/ou inventar algo novo, bem como inovar a partir de algo que já exista, durante os processos de produção e uso de determinado conhecimento científico;

- Falibilidade: discute como cada cientista identifica e lida com erros durante o processo de produção e uso do conhecimento científico;

- Incerteza: discute como cada cientista lida com as incertezas ${ }^{12}$, mais precisamente como ele toma consciência, se posiciona e, quando possível ou necessário, toma decisões frente a elas;

- Influência motivacional: discute as influências que as motivações de um cientista, sejam elas intrínsecas e/ou extrínsecas, podem sofrer e/ou exercer nos processos de produção e uso do conhecimento científico;

- Inteligência: discute características intelectuais de um cientista relacionadas a como ele compreende, relaciona e faz escolhas relacionadas a determinado conhecimento científico durante os processos de produção e uso do mesmo, de forma que seja possível pensar no cientista com inteligência "regular", isto é, que não tem uma inteligência fora do padrão (é um gênio);

- Limitação: discute como, devido a fatores internos e/ou externos, um cientista pode vivenciar dificuldades, ou mesmo se encontrar impossibilitado de dar continuidade ao processo de produção e uso de determinado conhecimento científico;

- Não linearidade do pensamento: discute como o pensamento de um cientista não se modifica linearmente ao longo dos processos de produção e uso do conhecimento científico;

- Objetividade: discute como um cientista pode pensar e agir de maneira direta, ou seja, ser focado em uma meta durante os processos de produção e uso do conhecimento científico;

- Personalidade: discute a personalidade $\mathrm{e}^{13}$ de um cientista visando, por exemplo,

12 Entendemos incerteza como algo para o qual não podemos prever precisamente o resultado ou criar uma explicação.

13 Entendemos personalidade como um conjunto de características marcantes próprias de um indivíduo e que o identifica e o diferencia dos demais indivíduos. Isto inclui, por exemplo, se ele é honesto e incorruptível em determinada situação ao longo dos processos de produção e uso do conhecimento científico. 
explicar o comportamento do mesmo em determinada situação ao longo dos processos de produção e uso do conhecimento científico;

- Racionalidade: discute como um cientista pode pensar e agir em conformidade com a razão, isto é, como ele pode relacionar pensamentos seguindo alguma lógica, durante os processos de produção e uso do conhecimento científico;

- Representação: discute a capacidade que um cientista possui de expressar uma ideia, seja de forma verbal, visual, matemática ou outra (por exemplo, ao pensar e/ou produzir analogias e modelos durante os processos de produção e uso do conhecimento científico); e

- Subjetividade: discute como os modos de pensar e/ou agir de um cientista se relacionam com suas próprias concepções prévias, que podem ser diferentes das de outro indivíduo e não necessariamente embasadas em alguma lógica explícita.

Nesta área, em especial, faz-se pertinente uma ressalva com relação a três aspectos: Objetividade, Racionalidade e Subjetividade. Essa se deve ao atual contexto em que estamos vivendo, denominado como tempos de pós-verdades, isto é, tempos em que indivíduos apelam às emoções e crenças pessoais ao invés de a fatos objetivos para moldar a opinião pública (Oxford Dictionary, 2016) e que, portanto, pode ser considerada como uma opinião pública não informada/acrítica. Neste contexto, no qual os indivíduos tendem a ser extremistas, tais aspectos são de grande importância para que eles busquem por uma postura presente em uma espécie de continuum ${ }^{14}$. Isto porque, para um indivíduo que adota uma postura extremista, ou a Ciência é objetiva e racional ou ela é subjetiva. Em outras palavras, para tal indivíduo os aspectos são representados como: Objetividade e Racionalidade versus Subjetividade, implicando que, se há o reconhecimento da presença da subjetividade na construção da Ciência, seu status e credibilidade são diminuídos (como discutido, por exemplo, em El-Hani \& Machado, 2020; Martins, 2015). Sob esta perspectiva, ao elencarmos esses três aspectos em uma mesma área de conhecimento e caracterizarmos explicitamente cada um deles, temos a intenção de contribuir para que os indivíduos os entendam e reflitam sobre os mesmos para que a partir disso, talvez possam adotar uma postura em uma espécie de continuum ao invés de um extremo ou outro de tal continuum.

Esta mesma lógica foi seguida com relação aos aspectos Influência motivacional, Influência cultural, Influência sociopolítica e Influência histórica ${ }^{15}$, ou seja, a partir desses aspectos é possível que os indivíduos tomem consciência de que a Ciência não é neutra, isto é, de que ela influencia e é influenciada por diversos aspectos (como discutido em El-Hani \& Machado, 2020). Isto seria uma grande contribuição não apenas para a área de Educação em Ciências como também para a sociedade de um modo geral, visto que a adoção de posturas extremistas por parte dos indivíduos é algo histórico que, em tempos passados, era influenciada, por exemplo, pela religião e, em tempos de pós-

14 Assumimos como continuum a representação (ou a tentativa) de um equilíbrio entre os extremos.

15 Estes três últimos são caracterizados nas próximas seções. 
verdades, está sendo influenciada (particularmente) pela política (Neiva, 2020). Desta maneira, é fundamental promovermos uma educação científica mais a utêntica e, consequentemente, um processo de alfabetização científica mais amplo visando o desenvolvimento de uma opinião pública informada/crítica.

\section{Antropologia da Ciência}

A Antropologia é uma área que estuda o homem no sentido mais amplo, isto é, no sentido da humanidade. Esta área pode ser subdivida ${ }^{16} \mathrm{em}$ : (i) Antropologia Biológica ou Física, que estuda o homem em sua dimensão biológica, por exemplo, sua origem, evolução e variações físicas; (ii) Antropologia Social ${ }^{17}$ ou Cultural ${ }^{18}$, que estuda o homem e as diferentes culturas, ou seja, a diversidade cultural humana; (iii) Antropologia Linguística, que estuda o homem e a linguagem (idioma, fala e linguagem), assim como os desdobramentos e as nuances envolvidas na linguagem humana; e (iv) Antropologia Arqueológica, que estuda o homem do passado e do presente a partir da análise de vestígios materiais como, por exemplo, fósseis, pinturas, obras de arte e arquitetônica, intervenções no meio ambiente. Assim, cada subdivisão possui questões específicas e, apesar de a etnografia ser uma metodologia amplamente utilizada na área da Antropologia, cada subdivisão também faz uso de métodos específicos (explicitando assim que não existe "o" ou "um único" método), sendo o estudo do homem comum a todas elas.

Além de estudar o homem, a Antropologia da Ciência estuda também a relação do mesmo com o conhecimento científico, considerando que a produção deste conhecimento é uma forma de ação social, e que seu desenvolvimento é uma forma de produção cultural. Sendo assim, assumimos que o estudo da Antropologia da Ciência se relaciona aos processos de produção e desenvolvimento do conhecimento científico a partir de aspectos como, por exemplo:

- Incomensurabilidade: discute o conceito de cultura ${ }^{19}$, de maneira que tais discussões resultem nas ideias de que não existe cultura boa ou ruim, melhor ou pior; existem diferentes culturas. Portanto, o mesmo conhecimento científico pode ser construído, interpretado e valorizado de maneiras diferentes, de

16 Essas subdivisões podem diferir dependendo da origem dos autores que as propõem, por exemplo, América Latina, Estados Unidos da América e Europa. Por este motivo, quando necessário, para uma melhor compreensão de nossas ideias, optamos por apresentar as diferentes formas em que essas subdivisões podem aparecer, bem como a relação entre as mesmas.

17 A Antropologia Social se difere da Sociologia no objeto de investigação. A Sociologia estuda o homem enquanto sociedade e a Antropologia Social estuda a influência dessa sociedade sobre o homem.

18 Autores norte-americanos adotam apenas o termo Antropologia Cultural, pois entendem que Antropologia Social e Antropologia Cultural são áreas distintas. Na visão norte-americana, a Antropologia Cultural estuda a diversidade cultural humana, tanto de grupos contemporâneos, como extintos. Isto se difere da Antropologia Social na medida em que o conceito de sociedade é mais abrangente do que o de cultura, visto que uma sociedade pode ser constituída de indivíduos que manifestam diferentes culturas.

19 Entendemos cultura como um conjunto de crenças, hábitos, formas de vestir, pensar, agir, falar, comer, caminhar, rezar, entre outros, ou seja, é o que é passado, adquirido, aprendido, vivido e compartilhado entre os indivíduos (Laraia, 2001). 
acordo com as diferentes culturas; e

- Influência cultural: discute as influências ${ }^{20}$ que a cultura pode sofrer e/ou exercer em relação a determinado conhecimento científico. Assim, indivíduos que manifestam diferentes culturas podem interpretar um mesmo fenômeno de maneiras diferentes.

\section{Sociologia da Ciência}

É uma área que estuda como ocorre o processo de produção do conhecimento científico analisando as interações do indivíduo, no caso o cientista, em sociedade. Portanto, os estudos dessa área evidenciam que a Ciência é uma prática social e envolvem aspectos como, por exemplo:

- Aceitabilidade: discute como o conhecimento é produzido, comunicado, avaliado, revisado e validado pelos cientistas para que seja aceito como científico;

- Credibilidade: discute o status que os cientistas, as instituições, os prêmios (por exemplo, o Nobel) e/ou a própria Ciência possuem frente à comunidade científica e/ou à sociedade;

- Falibilidade: discute como os cientistas identificam e lidam com erros durante o processo de produção do conhecimento científico, em uma perspectiva social, ou seja, como eles se articulam na comunidade acadêmica perante os erros, sejam seus ou de outro(s) cientista(s);

- Incerteza: discute como os cientistas, enquanto grupo de profissionais, lidam com as incertezas, mais precisamente como eles tomam consciência, se posicionam e, quando possível ou necessário, tomam decisões frente a elas;

- Influência sociopolítica: discute as influências que a sociedade na qual os cientistas estão inseridos e a política (local ou global) podem sofrer e/ou exercer durante o processo de produção do conhecimento científico. Por exemplo, a Sociologia da Ciência pode discutir como questões sociais e políticas iluminadas por diferentes posturas influenciam no desenvolvimento de pesquisas sobre um determinado tema e/ou como as pesquisas realizadas interferem no meio social e político; e

- Interação entre cientistas: discute os diferentes modos de interação entre cientistas, por exemplo, parcerias, contribuições, discordâncias e disputas durante o processo de produção do conhecimento científico.

\section{Economia da Ciência}

É uma área que estuda os impactos sofridos e/ou exercidos pela mercantilização ${ }^{21}$ e comercialização ${ }^{22}$ do conhecimento científico nas etapas de produção, desenvolvimento

20 Advindas, por exemplo, de posturas relacionadas à degradação do meio ambiente, ao racismo, ao feminismo, entre outras.

21 Mercantilização é o ato de transformar algo em mercadoria (Knuuttila, 2013).

22 Comercialização é o ato de colocar algo à venda (Knuuttila, 2013). 
e aplicação do mesmo, assim como alguns de seus aspectos:

- Acesso ao conhecimento: discute a questão da exclusividade do acesso ao conhecimento científico e suas implicações no valor monetário agregado ao mesmo, além de quem pode usufruir, direta ou indiretamente, de tal conhecimento;

- Aplicabilidade: discute o interesse das instituições que estão envolvidas nos processos de produção, desenvolvimento e/ou aplicação do conhecimento científico na utilização do mesmo;

- Competitividade: discute a competitividade entre instituições ao longo dos processos de produção, desenvolvimento e aplicação do conhecimento científico, visando a obtenção de patentes e/ou o reconhecimento da inovação;

- Fonte de financiamento: discute a variedade de instituições, incluindo universidades, centros de pesquisas, laboratórios industriais, agências governamentais, empresas spin-off ${ }^{23}$, entre outras, responsáveis pelo financiamento de pesquisas científicas;

- Investimento econômico: discute como o investimento ao longo dos processos de produção, desenvolvimento e aplicação do conhecimento científico é gradativo e depende tanto dos resultados desses processos quanto de fatores sociais, políticos, ambientais, entre outros;

- Produtividade: discute o interesse das instituições que estão envolvidas nos processos de produção, desenvolvimento e aplicação do conhecimento científico na produtividade, em termos de retorno financeiro;

- Publicidade: discute o interesse das instituições que estão envolvidas nos processos de produção, desenvolvimento e aplicação do conhecimento científico na divulgação do mesmo, com objetivo de obter financiamento e/ ou mercantilização e comercialização; e

- Viabilidade: discute o processo de avaliação para definir e/ou justificar os investimentos em pesquisas científicas.

\section{História da Ciência}

É uma área que estuda o desenvolvimento dos conhecimentos científicos ao longo do tempo, isto é, a modificação das ideias relacionadas à Ciência e à produção e/ou modificação de ideias em contextos passados e/ou contemporâneos. Assim, entendemos que seus principais aspectos são:

- Influência histórica: discute as influências que o contexto histórico pode sofrer e/ou exercer em relação aos processos de produção e uso de determinado conhecimento científico ao longo do tempo;

- Multiplicidade: discute sobre as diversas narrativas de, e/ou interpretações diferentes para, um mesmo episódio histórico em relação a determinado conhecimento científico;

23 Spin-offé uma empresa derivada, isto é, uma nova empresa que se originou de outra. 
- Não linearidade: discute a não existência de um único caminho para o desenvolvimento do conhecimento científico, incluindo os resgastes de ideias apresentadas em pesquisas anteriores, os imprevistos e as mudanças nas pesquisas sobre um determinado conhecimento científico que foram ocorrendo ao longo do tempo;

- Progressividade: discute o processo pelo qual um determinado conhecimento científico foi produzido, comunicado, avaliado, revisado e validado, de maneira gradativa ao longo do tempo. Assim, fica evidenciado que o conhecimento não é construído de uma única vez e demanda um tempo necessário para que os processos de produção do conhecimento científico ocorram;

- Provisoriedade: discute a ocorrência de mudanças em um determinado conhecimento científico ao longo do tempo, havendo o abandono de algumas ideias em detrimento de novas construções, o que é consequência de o processo ser dinâmico, isto é, não linear e progressivo.

\section{Ampliando a Analogia}

Retomando a analogia à London Eye (Figura 1), ao propormos e caracterizarmos os aspectos de $\mathrm{NdC}$ presentes em cada uma das áreas de conhecimento, percebemos a possibilidade de extensão da mesma. De acordo com Justi e Erduran (2015), a Ciência pode ser visualizada a partir de uma única cápsula (na perspectiva de um indivíduo que está dentro de uma delas) ou de várias ao mesmo tempo (na perspectiva de um observador externo). Na representação visual analógica para o MoCEC v.2 (Figura 3), a Ciência continua podendo ser visualizada a partir de uma única cápsula ou de várias ao mesmo tempo. Mas, além disto, ela pode ser visualizada a partir da integração da "base filosófica" com uma ou mais das áreas de conhecimento (representadas por cápsulas), por exemplo, quando uma determinada cápsula (Filosofia, Psicologia, Antropologia, Sociologia, Economia ou História da Ciência) passa pela "base filosófica" da rodagigante fazendo com que o "ar filosófico" entre nela e permeie os olhares dos indivíduos que estão naquela cápsula ou daqueles que a observam externamente.

Ainda em relação à representação visual para o MoCEC v.2 (Figura 3), percebemos a possibilidade de extensão da analogia no que se refere à posição que o indivíduo ocupa dentro da cápsula. Por exemplo, o aspecto Influência (especificada como motivacional, cultural, sociopolítica e histórica) aparece em muitas das áreas representadas pelas cápsulas. No domínio fonte original, o indivíduo entra em uma cápsula para visualizar Londres sob vários ângulos. Então, se um indivíduo se posiciona dentro de cada cápsula em um ângulo específico, ele pode visualizar Londres sob a perspectiva de tal ângulo. Voltando ao domínio analógico, tal indivíduo poderia visualizar a Ciência sob a perspectiva da área representada pela cápsula na qual ele estaria e sob o ângulo no qual ele estaria se posicionando naquela cápsula (por exemplo, sob a perspectiva da área de História da Ciência e sob o ângulo do aspecto Influência histórica ou sob a perspectiva da área de Psicologia da Ciência e sob o ângulo do aspecto Influência motivacional). 
Essa extensão não pode ser generalizada para todos os aspectos de $\mathrm{NdC}$, visto que apenas alguns têm significados semelhantes (expresso em nomes total ou parcialmente iguais). Isto vai ao encontro do nosso entendimento de que a Ciência apresenta caráter amplo e integrado. Entretanto, para que seja possível essa integração, é necessário ter clareza da existência de várias Ciências e de que as mesmas possuem características que podem ser comuns a outras Ciências, assim como possuem características específicas a cada uma delas (como discutido por Irzik e Nola, $(2011,2014)$ ).

Para finalizar, como Justi e Erduran (2015), nós consideramos as críticas apresentadas às listas de princípios e nos baseamos na proposta de Allchin $(2011,2012 b$, 2013) para propor nossas ideias. Além disto, nós nos baseamos também na proposta de Erduran e Dagher (2014) para ampliar o MoCEC, produzindo o MoCEC v.2. Isto porque tais propostas contribuem para solucionar alguns dos diversos problemas que as ideias apresentadas em listas de princípios possuem. Contudo, como comentado anteriormente, o MoCEC v.2 se justifica devido ao fato de caracterizar detalhada e didaticamente o que seria cada um dos aspectos de $\mathrm{NdC}$ a serem introduzidos no ensino de Ciências, assim como de ter uma representação visual que favorece seu entendimento, especialmente por professores. Assim, nossa principal contribuição se relaciona à dimensão $o$ que ensinar sobre Ciências (de acordo com Martins, 2015). Por este motivo, a utilização do MoCEC v.2 pode contribuir para promover uma educação científica mais autêntica e, consequentemente, emancipatória, na medida em que pode favorecer a formação de cidadãos crítico-reflexivos (Sasseron \& Carvalho, 2011), isto é, o desenvolvimento de uma visão mais ampla sobre Ciências e, portanto, de uma opinião pública informada/crítica.

\section{Potencialidades e Perspectivas}

Visando discutir as potenciais contribuições do MoCEC v.2, inicialmente optamos por apresentar uma organização sintética das áreas de conhecimento representadas no modelo, assim como de seus respectivos aspectos de NdC (Figura 4). Assim, o leitor poderá identificar mais facilmente quais aspectos estão presentes em cada área e quais aparecem em mais de uma área (aspecto identificado por nome total ou parcialmente igual em diferentes áreas).

Ressaltamos que, como Justi e Erduran (2015) ao apresentar as diversas perspectivas disciplinares, nossa intenção ao propor, caracterizar e apresentar esses aspectos de $\mathrm{NdC}$ não é a de que eles sejam exaustivos, mas sim representativos dos diversos aspectos que podem se relacionar a várias áreas de conhecimento no contexto de Educação em Ciências. 


\begin{tabular}{|c|c|c|c|c|c|c|}
\hline $\begin{array}{l}\text { Áreas de } \\
\text { Conhecimento }\end{array}$ & \multirow{2}{*}{$\begin{array}{c}\text { Filosofia } \\
\text { da Ciência }\end{array}$} & \multirow{2}{*}{$\begin{array}{l}\text { Psicologia } \\
\text { da Ciência }\end{array}$} & \multirow{2}{*}{$\begin{array}{c}\text { Antropologia } \\
\text { da Ciência }\end{array}$} & \multirow{2}{*}{$\begin{array}{l}\text { Sociologia } \\
\text { da Ciência }\end{array}$} & \multirow{2}{*}{$\begin{array}{l}\text { Economia } \\
\text { da Ciência }\end{array}$} & \multirow{2}{*}{$\begin{array}{l}\text { História } \\
\text { da Ciência }\end{array}$} \\
\hline Aspectos de NdC & & & & & & \\
\hline Epistemologia & $\mathrm{x}$ & & & & & \\
\hline Ética & $\mathrm{x}$ & & & & & \\
\hline Lógica & $\mathrm{x}$ & & & & & \\
\hline Complexidade & & $\mathrm{x}$ & & & & \\
\hline Criatividade & & $\mathrm{x}$ & & & & \\
\hline Falibilidade & & $\mathrm{x}$ & & $\mathrm{x}$ & & \\
\hline Incerteza & & $\mathrm{x}$ & & $\mathrm{x}$ & & \\
\hline Influência & & motivacional & cultural & sociopolítica & & histórica \\
\hline Inteligência & & $x$ & & & & \\
\hline Limitação & & $x$ & & & & \\
\hline Não linearidade & & do pensamento & & & & $x$ \\
\hline Objetividade & & $\mathrm{x}$ & & & & \\
\hline Personalidade & & $\mathrm{x}$ & & & & \\
\hline Racionalidade & & $\mathrm{x}$ & & & & \\
\hline Representação & & $\mathrm{x}$ & & & & \\
\hline Subjetividade & & $\mathrm{x}$ & & & & \\
\hline Incomensurabilidade & & & $\mathrm{x}$ & & & \\
\hline Aceitabilidade & & & & $\mathrm{x}$ & & \\
\hline Credibilidade & & & & $\mathrm{x}$ & & \\
\hline $\begin{array}{l}\text { Interação entre } \\
\text { cientistas }\end{array}$ & & & & $\mathrm{x}$ & & \\
\hline $\begin{array}{l}\text { Acesso ao } \\
\text { conhecimento }\end{array}$ & & & & & $\mathrm{x}$ & \\
\hline Aplicabilidade & & & & & $\mathrm{x}$ & \\
\hline Competitividade & & & & & $\mathrm{x}$ & \\
\hline $\begin{array}{l}\text { Fonte de } \\
\text { financiamento }\end{array}$ & & & & & $\mathrm{x}$ & \\
\hline $\begin{array}{l}\text { Investimento } \\
\text { econômico }\end{array}$ & & & & & $\mathrm{x}$ & \\
\hline Produtividade & & & & & $\mathrm{x}$ & \\
\hline Publicidade & & & & & $\mathrm{x}$ & \\
\hline Viabilidade & & & & & $\mathrm{x}$ & \\
\hline Multiplicidade & & & & & & $\mathrm{x}$ \\
\hline Progressividade & & & & & & $\mathrm{x}$ \\
\hline Provisoriedade & & & & & & $\mathrm{x}$ \\
\hline
\end{tabular}

Figura 4. Organização sintética das áreas de conhecimento representadas no MoCEC v.2 e de seus respectivos aspectos 
A Figura 4 evidencia que o MoCEC v.2 caracteriza a Ciência a partir de seis principais áreas de conhecimento às quais se associam 37 aspectos de $\mathrm{NdC}$ no total, sendo três deles relacionados à Filosofia da Ciência; 13 à Psicologia da Ciência; dois à Antropologia da Ciência; seis à Sociologia da Ciência; oito à Economia da Ciência; e cinco à História da Ciência. Alguns desses aspectos são comuns a mais de uma área como, por exemplo, os aspectos Falibilidade e Incerteza que são comuns à Psicologia e à Sociologia da Ciência. Além desses, temos também o aspecto Não linearidade (com complementos) que é comum à Psicologia e à História da Ciência. Por fim, temos o aspecto Influência (com variações) que é comum às áreas de Psicologia, Antropologia, Sociologia e História da Ciência. Contudo, mesmo que os nomes dos aspectos sejam os mesmos (total ou parcialmente), eles representam diferentes perspectivas em cada área de conhecimento, configurando um ponto de vista diferente no modelo. Neste mesmo sentido, considerando a presença do elemento "base filosófica", os aspectos da área de Filosofia da Ciência, especialmente Ética, permeiam todas as outras áreas. Assim, a Figura 4 favorece a visualização da concepção de Ciências expressa no MoCEC v.2.

Com relação ao uso do MoCEC v.2 como um suporte para professores no planejamento de situações de ensino mais autênticas, tendo entendido o significado de cada aspecto de NdC, o professor pode, a partir da Figura 4, identificar mais facilmente quais aspectos e relacionados a quais áreas ele deseja introduzir, de maneira contextualizada, explícita e integrada, em uma atividade. Contudo, a quantidade de áreas de conhecimento e aspectos de $\mathrm{NdC}$ que podem ser inseridos e discutidos em um contexto de ensino vai depender do contexto em que os estudantes estiverem inseridos, da atividade e das informações contidas na mesma, das ideias prévias que os estudantes podem expressar e/ou pesquisar no momento, e dos objetivos do professor naquele contexto de ensino particular.

Nesse sentido, a título de exemplificação, o MoCEC v.2 já foi utilizado como fundamentação teórica para propor atividades baseadas no filme O Menino que Descobriu o Vento $^{24}$ voltadas para estudantes do Ensino Médio, com o objetivo de introduzir aspectos de $\mathrm{NdC}$, de maneira contextualizada, explícita e integrada, no ensino de Ciências (Siqueira, 2019). Para a elaboração de uma das atividades, a autora/ professora selecionou alguns recortes do filme nos quais aspectos de $\mathrm{NdC}$, segundo o detalhamento de seus significados apresentados no modelo, podiam ser identificados nas falas e ações dos personagens. Por exemplo, o recorte 1, nomeado por Siqueira (2019) como Curiosidade de William ${ }^{25}$, retrata a curiosidade do menino ao comparar o "esqueleto" interno do aparelho de rádio de seu pai, que funcionava perfeitamente, com o do seu vizinho que não funcionava. Além disso, o recorte mostra que o menino insistiu por dias no conserto do aparelho de rádio, até conseguir fazê-lo. A partir desse recorte é possível inserir e discutir, de maneira contextualizada e explícita, os aspectos Criatividade e Personalidade, ambos da área de Psicologia da Ciência. Por outro lado, afirmar que isto foi feito de maneira integrada só é possível ao apresentarmos/analisarmos

24 https://www.netflix.com/br/title/80200047

25 William é o protagonista do filme. 
a atividade como um todo, pois somente a partir do somatório de recortes é possível discutir alguns conteúdos científicos curriculares da disciplina Física relacionados à produção de energia (eólica, no caso do filme).

Diante disso, pensando no contexto da Educação Básica, os nomes, os significados e as respectivas áreas dos aspectos de $\mathrm{NdC}$, assim como a representação visual analógica do MoCEC v.2 são apresentados didaticamente com o objetivo de auxiliar o professor na elaboração e na condução de atividades de ensino. Caso contrário, o modelo se reduziria a uma lista de aspectos de $\mathrm{NdC}$ que poderia ser apresentada de maneira declarativa para os estudantes, algo amplamente criticado na literatura (por exemplo, Allchin, 2011, 2013, 2017; Erduran \& Dagher, 2014; Irzik \& Nola, 2011, 2014; Justi \& Erduran, 2015; Matthews, 2012; McComas, 2008; Nielsen, 2013; Osborne et al., 2003; van Dijk, 2011; Weinstein, 2008; Wong \& Hodson, 2010). Entretanto, ressaltamos que, no momento de discussão das atividades, o professor não deve apresentar os nomes, os significados e as respectivas áreas dos aspectos de $\mathrm{NdC}$ aos estudantes, e sim as ideias relacionadas aos mesmos (e relações entre as mesmas), caso elas não sejam apresentadas pelos próprios estudantes.

Com relação ao contexto da Educação Superior, pensando na formação (inicial e/ou continuada) de professores, a utilização do modelo seria diferente. Os nomes, os significados e as respectivas áreas dos aspectos de $\mathrm{NdC}$ não só podem, como devem, ser apresentados aos (futuros) professores para ampliar seus próprios conhecimentos e para que eles possam vir a utilizar o modelo como um suporte no planejamento de situações de ensino mais autênticas com propriedade. Todavia, sugerimos que, antes de tais professores tomarem conhecimento do MoCEC v.2, eles vivenciem atividades baseadas no mesmo para que, assim, como discutido anteriormente, o processo formativo não seja baseado em um ensino declarativo. Além disso, acreditamos ser essencial que professores acreditem na importância de promover uma educação científica mais autêntica e a insiram em seus objetivos de ensino e de aprendizagem. Por esse motivo, atualmente, estamos desenvolvendo um estudo que utiliza o MoCEC v.2 para fundamentar a elaboração de atividades de diferentes naturezas (investigativa, histórica e argumentativa) e envolvendo diferentes contextos (cotidiano, científico e sociocientífico) voltadas para licenciandos de um curso de Química. Isto porque o fato de vivenciarem atividades que vão ao encontro dessa perspectiva de educação pode contribuir para que eles acreditem no potencial de, e promovam, uma educação científica mais autêntica.

Com relação ao uso do MoCEC v.2 como uma ferramenta de análise de dados coletados em contextos de ensino, a partir do entendimento dos elementos apresentados na Figura 4, o analista pode identificar mais facilmente quais aspectos de $\mathrm{NdC}$, concernentes a quais áreas de conhecimento, foram manifestados e/ou vivenciados pelos sujeitos de pesquisa. Além disto, caso tais dados sejam analisados ao longo de um certo tempo, o analista pode ter elementos para compreender o processo de construção e desenvolvimento do conhecimento científico por parte dos sujeitos envolvidos. 
Entretanto, para que a ferramenta seja utilizada de maneira adequada, o recorte e/ou a unidade de análise não deve(m) ser constituído(s) de dados fragmentados. Mesmo que o analista tenha interesse em utilizar a ferramenta para fragmentos específicos como, por exemplo, transcrição de falas, é necessário que a mesma esteja situada, isto é, inserida no contexto em que foi proferida. Portanto, é fundamental que se saiba exatamente o que aconteceu ou foi falado antes e depois do trecho transcrito que se pretende analisar. Nesse sentindo, recomendamos ao analista que, antes de usar a ferramenta, descreva seus dados, e que suas transcrições sejam situadas em meio a essa descrição. Isso foi feito ao analisarmos dados coletados em um contexto de ensino com o objetivo de compreender as visões sobre Ciências de estudantes do Ensino Médio e as relações das mesmas com o Ensino Fundamentado em Modelagem em contextos cotidiano, científico e sociocientífico (Santos, 2019).

Nessa perspectiva, os aspectos de $\mathrm{NdC}$ podem ser utilizados pelo analista como categorias bem definidas na análise de dados coletados em quaisquer contextos de ensino. Por esse motivo, nos preocupamos em dar nome e caracterizar detalhadamente cada um dos aspectos identificados e propostos, relacionados às respectivas áreas de conhecimento representadas no MoCEC v.2. Ademais, entendemos que esta tenha sido a maior contribuição desta pesquisa para a área de Educação em Ciências. Isto porque é comum encontrarmos o termo "aspectos" e/ou "aspectos de $\mathrm{NdC}$ " na literatura da área, mas sem que os mesmos sejam identificados e seus significados claramente explicitados. Também é comum encontrarmos, por exemplo, que determinadas informações estão relacionadas aos aspectos econômicos, históricos, entre outros. Contudo, até o presente momento (início de 2020), não encontramos na literatura da área trabalhos que, além de estabelecerem esta relação geral, identifiquem e caracterizem tais aspectos.

Nesse sentido, o MoCEC v.2 está sendo utilizado para analisar dados coletados em um contexto de ensino de formação de professores de Química com objetivos de compreender: (i) as visões sobre Ciências de licenciandos, e as relações das mesmas com uma disciplina que foi planejada e ministrada de maneira contextualizada; e (ii) os conhecimentos de conteúdo de $\mathrm{NdC}$ mobilizados por licenciandos ao longo de um processo formativo baseado no modelo. Além disso, neste mesmo contexto, o MoCEC v.2 também será utilizado pelos licenciandos para analisar uma atividade de ensino baseada no modelo, elaborada por eles.

Com relação às perspectivas do MoCEC v.2, apesar de este ser um artigo de natureza teórica, diferentemente de Justi e Erduran (2015), nós dispusemos de alguns suportes empíricos na ampliação do mesmo. Diante disso, à medida que explicamos, exemplificamos e discutimos sobre as duas funções com as quais o modelo pode ser utilizado, pudemos apresentar exemplos de alguns estudos concluídos recentemente e/ ou em andamento. Todavia, isso não exclui a necessidade de realização de novos estudos, isto é, da apresentação de possíveis questões a serem investigadas. Por exemplo, diante do atual contexto de pandemia (causada pelo coronavírus SARS-CoV-2) que estamos vivendo e dos problemas ocasionados pela mesma, talvez nunca tenha ficado tão 
explícito quanto agora a necessidade da integração de diferentes áreas de conhecimento para que um indivíduo se posicione a respeito de tais problemas, ou ainda, possa buscar soluções para os mesmos. Sob esta perspectiva, a utilização do MoCEC v.2 no ensino de Ciências pode favorecer tal integração. Contudo, seriam necessários estudos que analisassem se e como tal integração é favorecida, assim como estudos sobre a formação e o desenvolvimento de professores para que eles conduzissem o ensino na perspectiva aqui defendida.

Ressaltamos que, em todos os estudos mencionados para exemplificar o uso do MoCEC v.2, os aspectos de NdC foram utilizados como categorias bem definidas para a elaboração de atividades e/ou análise de dados em contextos de ensino, mais especificamente, para identificação de aspectos possíveis de serem introduzidos de maneira contextualizada e/ou explícita e/ou integrada, no ensino de Ciências/Química, independentemente do nível de ensino. Além disso, muitos desses estudos foram e estão sendo desenvolvidos por professores e pesquisadores além dos que estiveram envolvidos na ampliação do modelo que resultou no MoCEC v. 2 - sujeitos estes que poderão apresentar suas avaliações sobre a abrangência e limitações desta nova versão do modelo. Nesse sentido, os resultados desses estudos também estarão contribuindo para a validação da mesma.

Finalmente, destacamos que como muitos novos modelos propostos ao longo da história, o MoCEC v.2 se baseia em pressupostos de outros anteriores (principalmente, mas não apenas, do MoCEC), mas tem elementos relacionados à sua essência que são distintos ${ }^{26}$. Assim, alguns pontos importantes diferenciam a proposta apresentada neste artigo das demais apresentadas por outros autores. Inicialmente, ela não se trata de uma lista de princípios, como a apresentada por Lederman e seus colaboradores. Ao contrário, ela se alinha a uma visão de Ciência contemporânea e ampla, como as apresentadas por Allchin (baseada na ideia de Ciência Integral) e por Irzik e Nola e Erduran e Dagher (baseada na ideia de Semelhança de Família, proposta por Wittgenstein). Nossa proposta vai além delas, tentando caracterizar uma perspectiva para instrumentalizar professores a pensar Ciência como um todo, buscando orientar o entendimento e a reflexão sobre seus processos de construção. Assim, o MoCEC v.2 se propõe a orientar o entendimento e a reflexão sobre Ciências, direcionando os olhares para como os diversos aspectos de NdC a caracteriza, ao mesmo tempo em que tenta não engessá-la. Além disso, a multiplicidade de áreas de conhecimento e aspectos de $\mathrm{NdC}$ contemplados em tal modelo evidencia o próprio status de diversidade e construção contínua da Ciência, uma vez que prevê a possibilidade do surgimento (ou da consideração) de novas áreas e aspectos.

Dessa forma, mesmo em relação a outras perspectivas que apresentam uma visão de Ciência contemporânea e ampla, o MoCEC v.2 possui três características fundamentais que tendem a potencializar seu uso em contextos de ensino e na análise desses: (i) ele se mostra mais didático, na medida em que busca orientar o pensamento

26 Em termos de um programa de pesquisa Lakatosiano, mantivemos o núcleo (hard core), mas modificamos a faixa protetora (protective belt). 
do professor e/ou pesquisador pelas grandes áreas de conhecimento e pelos diversos aspectos de $\mathrm{NdC}$ a partir da devida caracterização de cada um; (ii) ele é representado por uma analogia que favorece a compreensão dos papeis e das relações entre as diversas áreas de conhecimento e seus respectivos aspectos; e (iii) ele reflete o dinamismo e multiplicidade da Ciência.

Ainda com relação ao uso de representações analógicas para favorecer o entendimento de um modelo por parte de professores, isto foi feito anteriormente de maneira teórica por Erduran e Dagher (2014) e de maneira empírica em estudos desenvolvidos em um único contexto de coleta de dados envolvendo professores em formação (Erduran \& Kaya, 2018; Kaya et al., 2019). Entretanto, como destacamos anteriormente, a representação utilizada por tais autoras envolve um domínio fonte não familiar a muitos professores e no qual nem todas as relações entre os elementos do modelo estão claramente representadas. Em função disto, e em consonância com os princípios que definem condições para o estabelecimento de boas analogias (por exemplo, em Gentner, 1989), consideramos que ela pode não contribuir para o mapeamento tão direto entre os dois domínios da analogia (e a consequente visualização dos elementos presentes no modelo representado e das relações entre eles) como ocorre no caso da analogia com um domínio fonte como uma roda-gigante. Isto justifica nossa preocupação não só com a ampliação do modelo em si, mas também com a alteração de sua representação visual e com a apresentação de explicações claras a ela relacionadas visando contribuir para o entendimento de professores e pesquisadores que possam vir a utilizar o MoCEC v.2.

Assim, a partir dos estudos baseados no MoCEC v.2 e da divulgação dos resultados oriundos dos mesmos, em um futuro próximo, esperamos promover reflexões críticas sobre como nós, professores e pesquisadores, estamos contribuindo para a promoção e o alcance de uma educação científica mais autêntica - e, consequentemente, emancipatória, na medida em que pode favorecer a formação de cidadãos críticoreflexivos (Sasseron \& Carvalho, 2011) a partir do desenvolvimento de uma visão mais ampla sobre Ciências e, portanto, de uma opinião pública informada/crítica por parte de estudantes. Ao mesmo tempo, esperamos que ao fazer um tour na representação visual do MoCEC v.2, professores e pesquisadores possam ampliar suas visões sobre Ciências, de forma que as ideias discutidas neste artigo, e em outros que relatem os estudos em desenvolvimento, ampliem as perspectivas de pesquisas relacionadas à introdução de aspectos de NdC na área de Educação em Ciências, fomentando diálogos crescentes entre todos os interessados nesta temática.

\section{Agradecimentos}

As autoras agradecem: aos integrantes do Grupo de Pesquisa REAGIR Modelagem e Educação em Ciências e às três pesquisadoras especialistas na área, por terem contribuído na validação do MoCEC v.2; à Izabella Martins, por ter contribuído na produção da representação visual analógica do modelo; à CAPES e ao CNPq, pelos 
auxílios financeiros que lhes possibilitaram dedicar tempo para desenvolver esta pesquisa; e aos árbitros anônimos e ao editor associado da RBPEC, Cristiano Moura, pela leitura crítica da versão inicialmente submetida do artigo e apontamentos que contribuíram para a produção desta versão.

\section{Referências}

Abd-El-Khalick, F. (2012). Nature of Science in Science Education: Towards a coherent framework for synergistic research and development. In B. J. Fraser, K. G. Tobin, \& C. J. McRobbie (Eds.), Second International Handbook of Science Education (pp. 1041-1060). Springer.

Abd-El-Khalick, F., Bell, R. L., \& Lederman, N. G. (1998). The Nature of Science and Instructional Practice: Making the unnatural natural. Science Education, 82(4), 417-436. https://doi.org/10.1002/(SICI)1098-237X(199807)82:4\%3C417::AIDSCE1\%3E3.0.CO;2-E

Allchin, D. (2004). Should the Sociology of Science Be Rated X? Science Education, 86(6), 934-946. https://doi.org/910.1002/sce.20026

Allchin, D. (2011). Evaluating Knowledge of the Nature of (Whole) Science. Science Education, 95(3), 518-542. https://doi.org/510.1002/sce.20432

Allchin, D. (2012a). How Can History and Philosophy of Science Contribute to Understanding the Nature of Science for Scientific Literacy?: Mapping research needs. Paper presented at the Conference on How Can the HPS Contribute to Contemporary U.S., Boston, Massachusetts.

Allchin, D. (2012b). The Minnesota Case Study Collection: New Historical Inquiry Case Studies for Nature of Science Education. Science \& Education, 21(9), 1263-1281. https:// doi.org/10.1007/s11191-011-9368-x

Allchin, D. (2013). Teaching the Nature of Science: Perspectives \& Resources. SHiPS Educational Press.

Allchin, D. (2014). From Science Studies to Scientific Literacy: A view from the classroom. Science \& Education, 23(9), 1911-1932. https://doi.org/10.1007/s11191-013-9672-8

Allchin, D. (2017). Beyond the Consensus View: Whole Science. Canadian Journal of Science, Mathematics and Technology Education, 17(1), 18-26. https://doi.org/10.1080/1 4926156.14922016.11271921

Allchin, D., Andersen, H. M., \& Nielsen, K. (2014). Complementary Approaches to Teaching Nature of Science: Integrating student inquiry, historical cases, and contemporary cases in classroom practice. Science Education, 98(3), 461-486. https:// doi.org/410.1002/sce.21111 
Archer, L., DeWitt, J., Osborne, J., Dillon, J., Willis, B., \& Wong, B. (2010). “Doing” Science versus "Being" a Scientist: Examining 10-and 11-year-old schoolchildren's constructions of science through the lens of identity. Science Education, 94(4), 617-639. https://doi.org/610.1002/sce.20399

Bayir, E., Cakici, Y., \& Ertas, O. (2014). Exploring Natural and Social Scientists' Views of Nature of Science. International Journal of Science Education, 36(8), 1286-1312. https:// doi.org/1210.1080/09500693.09502013.09860496

Cakici, Y., \& Bayir, E. (2012). Developing Children's Views of the Nature of Science through Role Play. International Journal of Science Education, 34(7), 1075-1091. https:// doi.org/1010.1080/09500693.09502011.09647109

Carvalho, B., \& Justi, R. (2019). O Caso Histórico Marie Curie: Investigando o Potencial da História da Ciência para Favorecer Reflexões de Professores em Formação sobre Natureza da Ciência. Alexandria: Revista de Educação em Ciência e Tecnologia, 12(1), 351-373. http://dx.doi.org/310.5007/1982-5153.2019v5012n5001p5351

Cunningham, C. M., \& Helms, J. V. (1998). Sociology of Science as a Means to a More Authentic, Inclusive Science Education. Journal of Research in Science Teaching, 35(5), 483499. https://doi.org/410.1002/(SICI)1098-2736(199805)199835:199805<199483::AIDTEA199802>199803.199800.CO;199802-L

Deng, F., Chen, D. T., Tsai, C. C., \& Chai, C. S. (2011). Students' Views of the Nature of Science: A critical review of research. Science Education, 95(6), 961-999. https://doi. org/910.1002/sce.20460

Diamond Jr, A. M. (1996). The Economics of Science. Knowledge and Policy: The International Journal of Knowledge Transfer and Utilization, 9(2-3), 6-49.

Diamond Jr, A. M. (2008). Economics of Science. In S. N. Durlauf \& E. Blume (Eds.), The New Palgrave Dictionary of Economics Online (pp. 1-27). Palgrave Macmillan.

Driver, R., Leach, J., Millar, R., \& Scott, P. (1996). Young people's images of science. Open University Press.

Dunbar, K. (2002). Understanding the Role of Cognition in Science: The science as category framework. In P. Carruthers, S. Stich, \& M. Siegal (Eds.), The Cognitive Basis of Science (pp. 154-170). Cambridge University Press.

Dunbar, K., \& Blanchette, I. (2001). The in Vivo/in Vitro Approach to Cognition: The case of analogy. Trends in Cognitive Sciences, 5(8), 334-339. https://doi.org/310.1016/ S1364-6613(1000)01698-01693

El-Hani, C. N., Machado, V. (2020). COVID-19: The need of an integrated and critical view. Ethnobiology and Conservation, 9(18), 1-20. https://doi.org/10.15451/ec2020-059.18-1-20 
Erduran, S., \& Dagher, Z. R. (2014). Reconceptualising the Nature of Science for Science Education: Scientific knowledge, practices and other family categories. Springer.

Erduran, S., Dagher, Z. R., \& McDonald, C. V. (2019). Contributions of the Family Resemblance Approach to Nature of Science in Science Education: A Review of Emergent Research and Development. Science \& Education, 28(3-5), 311-328. https:// doi.org/10.1007/s11191-019-00052-2

Erduran, S., Kaya, E. (2018). Drawing Nature of Science in Pre-service Science Teacher Education: Epistemic Insight Through Visual Representations. Research in Science Education, 48, 1133-1149. https://doi.org/10.1007/s11165-018-9773-0

Erduran, S., \& Mugaloglu, E. (2013). Interactions of Economics of Science and Science Education: Investigating the implications for science teaching and learning. Science \& Education, 22(10), 2405-2425. https://doi.org/10.1007/s11191-012-9519-8

Feist, G. J. (2012). The Psychology of Science is Off and Running but Where do We Go from Here? In R. W. Proctor, \& E. J. Capaldi (Eds.), Psychology of Science: Implicit and Explicit Processes (pp. 13-39). Oxford University Press.

Feist, G. J., \& Gorman, M. E. (1998). The Psychology of Science: Review and integration of a nascent discipline. Review of General Psychology, 2(1), 3-47. https://doi. org/10.1037/1089-2680.1032.1031.1033

Gentner, D. (1989). The mechanisms of analogical learning. In S. Vosniadou \& A. Ortony (Eds.), Similarity and analogical reasoning (pp. 199-241). Cambridge University Press.

Giere, R. N. (1992). Cognitive Models of Science. University of Minnesota Press.

Giere, R. N. (1998). Explaining Science: A cognitive approach. University of Chicago Press.

Giere, R. N. (2002). Scientific Cognition as Distributed Cognition. In P. Carruthers, S. Stich, \& M. Siegal (Eds.), The Cognitive Basis of Science (pp. 285-299). Cambridge University Press.

Gilbert, J. (2004). Models and Modelling: Routes to a more authentic science education. International Journal of Science and Mathematics Education, 2(2), 115-130. https://doi. org/110.1007/s10763-10004-13186-10764

Gilbert, J., \& Justi, R. (2016). Modelling-based Teaching in Science Education. Springer International Publishing.

Guerra-Ramos, M. T. (2012). Teachers' ideas about the nature of science: A critical analysis of research approaches and their contribution to pedagogical practice. Science \& Education, 21(5), 631-655. https://doi.org/10.1007/s11191-011-9395-7

Irzik, G. (2013). Introduction: Commercialization of academic science and a new agenda for science education. Science \& Education, 22(10), 2375-2384. https://doi.org/10.1007/ s11191-013-9583-8 
Irzik, G., \& Nola, R. (2011). A Family Resemblance Approach to the Nature of Science for Science Education. Science \& Education, 20(7-8), 591-607. https://doi.org/10.1007/ s11191-010-9293-4

Irzik, G., \& Nola, R. (2014). New Directions for Nature of Science Research. In M. R. Matthews (Ed.), International Handbook of Research in History, Philosophy and Science Teaching (pp. 999-1021). Springer.

Jiménez-Aleixandre, M. P., \& Duschl, R. (2015). Epistemic Practices and Scientific Practices: Theoretical and Educational Challenges. Paper presented at the 11th Conference of the European Science Education Research Association, Helsinki, Finland.

Justi, R., Almeida, B., \& Santos, M. (2019). Scientific Literacy: Going Beyond DecisionMaking. Paper presented at the 13th Conference of the European Science Education Research Association, Bologna, Italy.

Justi, R., \& Erduran, S. (2015). Characterizing Nature of Science: A supporting model for teachers. Paper presented at the Conference of the International History, Philosophy, and Science Teaching Group, Rio de Janeiro, Brazil.

Justi, R., \& Santos, M. (2019). Students' Functional Understanding of Nature of Science: Contributions from a Film-based Teaching Activity. Paper presented at the 92nd Annual International Conference of the National Association for Research in Science Teaching, Baltimore, USA.

Kaya, E., \& Erduran, S. (2016). From FRA to RFN: How the Family Resemblance Approach Can Be Transformed for Science Curriculum Analysis on Nature of Science. Science \& Education, 25(9-10), 1115-1133. https://doi.org/10.1007/s11191-016-9861-3

Kaya, E., Erduran, S., Aksoza, B., \& Akgun, S. (2019). Reconceptualised family resemblance approach to nature of science in pre-service science teacher education. International Journal of Science Education, 41(1), 21-47. https://doi.org/10.1080/09500 693.09502018.01529447

Knorr-Cetina, K. (1999). Epistemic Cultures: How the sciences make knowledge. Harvard University Press.

Knuuttila, T. (2013). Science in a New Mode: Good old (theoretical) science versus brave new (commodified) knowledge production? Science \& Education, 22(10), 2443-2461. https://doi.org/10.1007/s11191-012-9498-9

Laraia, R. B. (2001). Cultura: Um conceito antropológico. Jorge Zahar.

Latour, B. (1987). Science in Action. Harvard University Press.

Latour, B., \& Woolgar, S. (1986). Laboratory Life: The construction of scientific facts. Princeton University Press.

Lederman, J. S., \& Khishfe, R. (2002). Views of Nature of Science, Form D. Unpublished paper. Illinois Institute of Technology. 
Lederman, J. S., \& Ko, E. K. (2002). Views of Nature of Science, Form E. Unpublished paper. Illinois Institute of Technology.

Lederman, N. G. (2006). Syntax of Nature of Science within Inquiry and Science Instruction. In L. B. Flick \& N. G. Lederman (Eds.), Scientific Inquiry and Nature of Science (pp. 301-317). Springer.

Lederman, N. G., Abd-El-Khalick, F., Bell, R. L., \& Schwartz, R. S. (2002). Views of Nature of Science Questionnaire: Toward valid and meaningful assessment of learners' conceptions of nature of science. Journal of Research in Science Teaching, 39(6), 497-521. https://doi.org/410.1002/tea.10034

Lima, R. R. (2017). Desenvolvimento do Conhecimento de Professores sobre Natureza da Ciência: Contribuições da história da ciência. (Dissertação de Mestrado), Universidade Federal de Minas Gerais, Belo Horizonte. https://repositorio.ufmg.br/bitstream/1843/ BUOS-AWGLUA/1/dissertac_a_o__rachel_rodrigues_lima.pdf

Marcus, G. E., \& Fischer, M. (1986). Antropology as Cultural Critique: An experimental moment in the human sciences. University of Chicago Press.

Martins, A. F. P. (2015). Natureza da Ciência no ensino de ciências: uma proposta baseada em "temas" e "questões". Caderno Brasileiro de Ensino de Física, 32(3), 703-737. http://dx.doi.org/10.5007/2175-7941.2015v32n3p703

Matthews, M. R. (1998). In Defense of Modest Goals when Teaching about the Nature of Science. Journal of Research in Science Teaching, 35(2), 161-174, https://doi.org/110.1002/ (SICI)1098-2736(199802)199835:199802<199161::AID-TEA199806>199803.199800. CO;199802-Q

Matthews, M. R. (2012). Changing the Focus: From nature of science to features of science. In M. S. Khine (Ed.), Advances in Nature of Science Research (pp. 3-26). Springer.

McComas, W. F. (2008). Seeking Historical Examples to Illustrate Key Aspects of the Nature of Science. Science \& Education, 17(2-3), 249-263. https://doi.org/10.1007/ s11191-007-9081-y

Millar, R., \& Osborne, J. (1998). Beyond 2000: Science education for the future. King's College and London School of Education.

Moura, C., Camel, T., \& Guerra, A. (2020). A Natureza da Ciência pelas Lentes do Currículo: Normatividade curricular, contextualização e os centidos de ensinar sobre Ciências. Ensaio Pesquisa em Educação em Ciências, 22, 1-27. https://doi. org/10.1590/1983-21172020210114

Neiva, L. (2020). Desde Galileu, negação da ciência passou do campo religioso para o político, diz astrofísico. https://www.uol.com.br/tilt/noticias/bbc/2020/05/30/desdegalileu-negacao-da-ciencia-passou-do-campo-religioso-para-o-politico-diz-astrofisico. htm 
Nielsen, K. (2013). Scientific Communication and the Nature of Science. Science \& Education, 22(9), 2067-2086. https://doi.org/10.1007/s11191-012-9475-3

Olson, J. (2018). The Inclusion of the Nature of Science in Nine Recent International Science Education Standards Documents. Science \& Education, 27(7-8), 637-660. https://doi.org/10.1007/s11191-018-9993-8

Osbeck, L. M., Nersessian, N. J., Malone, K. R., \& Newstetter, W. C. (2011). Science as Psychology: Sense-making and identity in science practice. Cambridge University Press.

Osborne, J., Collins, S., Ratcliffe, M., Millar, R., \& Duschl, R. (2003). What "Ideas-aboutScience" Should Be Taught in School Science? A Delphi Study of the Expert Community. Journal of Research in Science Teaching, 40(7), 692-720. https://doi.org/610.1002/ tea. 1010

Oxford Dictionary. (2016). Oxford Dictionary 2016 word of the year. https:// en.oxforddictionaries.com/word-of-the-year/word-ofthe-year-2016

Pickering, A. (1995). The Mangle of Practice: Time, agency, \& science. The University of Chicago Press.

Roberts, D. A. (2011). Competing Visions of Scientific Literacy: The influence of a science curriculum policy image. In C. Linder, L. Östman, D. A. Roberts, P.-O. Wickman, G. Erickson, \& A. Mackinnon (Eds.), Exploring the Landscape of Scientic Literacy (pp. 1127). Routledge.

Rosenberg, A. (2005). Why Philosophy of Science? In A. Rosenberg (Ed.), The Philosophy of Science: A contemporary introduction (pp. 1-20). Routledge.

Santos, M. (2018). Uso da História da Ciência para Favorecer a Compreensão de Estudantes do Ensino Médio sobre Ciência. Revista Brasileira de Pesquisa em Educação em Ciências, 18(2), 641-668. https://doi.org/610.28976/21984-22686rbpec2018182641

Santos, M. (2019). Compreendendo Visões de Estudantes sobre Ciências e suas Relações com o Ensino Fundamentado em Modelagem em Contextos Cotidiano, Científico e Sociocientífico. (Dissertação de Mestrado), Universidade Federal de Minas Gerais, Belo Horizonte. https://repositorio.ufmg.br/bitstream/1843/BUOS-BBLJX2/1/ disserta_o__monique_santos.pdf

Sasseron, L. H., \& Carvalho, A. M. P. (2011). Alfabetização Científica: Uma revisão bibliográfica. Investigações em Ensino de Ciências, 16(1), 59-77.

Schwartz, R. S., Lederman, N. G., \& Lederman, J. S. (2008). An Instrument to Assess Views of Scientific Inquiry: The VOSI questionnaire. Paper presented at the Annual Meeting of the National Association for Research in Science Teaching, Baltimore, MD.

Shadish, W. R., Fuller, S., \& Gorman, M. E. (1994). Social Psychology of Science: A conceptual and empirical eesearch program. In W. R. Shadish \& S. Fuller (Eds.), The Social Psychology of Science (pp. 3-122). Guilford Press. 
Shadish, W. R., Houts, A. C., Gholson, B., \& Neimeyer, R. A. (1989). The Psychology of Science: An introduction. In B. Gholson, W. R. Shadish, R. A. Neimeyer, \& A. C. Houts (Eds.), Pshychology of Science: Contributions to metascience (pp. 1-16). Cambridge University Press.

Siqueira, E. C. P. (2019). A Inserção e Discussão de Aspectos de Natureza da Ciência em Sala de Aula a partir do Filme O Menino que Descobriu o Vento. (Trabalho de Conclusão de Curso), Universidade Federal de Minas Gerais, Belo Horizonte.

van Dijk, E. M. (2011). Portraying Real Science in Science Communication. Science Education, 95(6), 1086-1100. https://doi.org/1010.1002/sce.20458

Vermeir, K. (2013). Scientific Research: Commodities or commons? Science \& Education, 22(10), 2485-2510. https://doi.org/10.1007/s11191-012-9524-y

Weinstein, M. (2008). Finding Science in the School Body: Reflections on transgressing the boundaries of science education and the social studies of science. Science Education, 92(3), 389-403. https://doi.org/310.1002/sce.20267

Wong, S. L., \& Hodson, D. (2010). More from the Horse's Mouth: What scientists say about science as a social practice. International Journal of Science Education, 32(11), 1431-1463. https://doi.org/1410.1080/09500690903104465 
Monique Santos

https://orcid.org/0000-0001-6042-0312 Universidade Federal de Minas Gerais

Faculdade de Educação, Programa de Pós-graduação em Educação:

Conhecimento e Inclusão Social Belo Horizonte, Minas Gerais, Brasil moniquersqui@gmail.com

Poliana Maia

https://orcid.org/0000-0001-9778-4486 Universidade Federal de Viçosa Campus Florestal Instituto de Ciências Exatas e Tecnológicas Florestal, Minas Gerais, Brasil poliana.maia@ufv.br

Rosária Justi

https://orcid.org/0000-0001-6535-5046 Universidade Federal de Minas Gerais Instituto de Ciências Exatas

Departamento de Química Belo Horizonte, Minas Gerais, Brasil rjusti@ufmg.br

Submetido em 04 de abril de 2020

Aceito em 25 de junho de 2020

Publicado em 15 de julho de 2020 